\title{
Acción colectiva e imaginarios en contextos de interés medioambiental. Una etnografía a los Asentamientos pro Sustentabilidad en Chile ${ }^{1}$
}

\section{Collective action and imaginaries in contexts of environmental interest. An ethnography of the Pro-Sustainability Settlements in Chile}

\author{
Leonardo Cancino ${ }^{2}$
}

\begin{abstract}
Resumen
Desde mediados del siglo XIX, la noción de movimiento social fue asociada a la estructura de clases y a la conflictividad pública. A partir de las décadas de 1960 en Europa y de 1980 en Latinoamérica, esta concepción comienza a ser cuestionada, debido al surgimiento de actores y demandas que privilegian aspectos valóricos o identitarios. Como consecuencia, la noción de movimiento social se amplió para abordar a colectivos orientados hacia la transformación de aspectos específicos de la vida cotidiana. Uno de los actores que se visibiliza durante esta mutación de la acción colectiva fue el movimiento ecologista. Parte de él, se imbricó con la tradición de las colonias utópicas del siglo XIX y de las comunas contraculturales de la década de 1960 para dar origen a distintos tipos de asentamientos que sostienen discursos a favor del medioambiente o de la sustentabilidad, tales como ecoaldeas y comunidades ecológicas, reunidos aquí, bajo la noción de Asentamientos pro-Sustentabilidad (ApS). En este artículo y a través de una etnografía efectuada a dichos lugares, se interrogan las formas que adquiere la acción colectiva contemporánea en un contexto de motivaciones medioambientales. Se propone que los ApS, se configuran como un movimiento sociocultural que intersecta diversas identidades y que encuentra, en la "naturaleza" y en su polisemia, un significante con efectos y potencial articulatorios.
\end{abstract}

Palabras clave: Chile, Ecoaldeas, Movimientos sociales, Naturaleza, Territorialización.

\begin{abstract}
Since the mid-nineteenth century, the notion of social movement was associated with class structure and public conflict. From the 1960s in Europe and the 1980s in Latin America, this conception begins to be questioned, due to the emergence of actors and demands that privilege aspects of value or identity. As a consequence, the notion of social movement was broadened and began to address groups oriented towards the transformation of specific aspects of daily life. One of the actors visible during this mutation of the collective action was the environmental movement. Part of it, was intermingled with the tradition of the utopian colonies of the 19th century and the counterculture communes of the 1960 s, to give rise to different types of settlements that hold speeches in favor of the environment or sustainability, such as ecovillages and ecological communities, gathered here, under the notion of Pro-Sustainability Settlements (ApS). In this article and through an ethnography carried out at these places, the forms taken by contemporary collective action in a context of environmental motivations are questioned. It is proposed that the ApS are configured as a sociocultural movement that intersects diverse identities and that finds, in "nature" and in its polysemy, a signifier with articulatory effects and potential.
\end{abstract}

Keywords: Chile, Ecovillages, Nature, Social movements, Territorialization.

Recibido el 11 febrero 2018, aceptado el 19 noviembre 2018

Cómo citar: Cancino, L. (2018). Acción colectiva e imaginarios en contextos de interés medioambiental. Una etnografía a los Asentamientos pro Sustentabilidad en Chile. Investigaciones Geográficas, 56, 4579. https://doi.org/10.5354/0719-5370.2018.51555

1 Este artículo forma parte de la tesis "Acción colectiva e imaginarios en disputa. Etnografía a los Asentamientos pro Sustentabilidad en Chile", desarrollada en contexto del programa de Doctorado en Ciencias Sociales de la Universidad de Chile.

2 Facultad de Ciencias Sociales. Universidad de Chile. E-mail: leocancinop@hotmail.com

Este trabajo se realizó con el apoyo de beca CONICYT-PCHA/Doctorado Nacional/ 2015-21150831 


\section{Introducción}

\section{Mutaciones en la acción colectiva}

A lo largo de este trabajo, se abordan las transformaciones experimentadas por la acción colectiva en el contexto de su paulatino abandono de la política formal y su creciente orientación hacia los aspectos culturales. Es posible ilustrar estas transformaciones, a través de la identificación de dos periodos que acontecen primero en los países de altos ingresos, para posteriormente, hacerlo en Chile.

En el primer periodo, destaca la importancia ocupada por el movimiento obrero, que será considerado como el sujeto revolucionario central (Flacks, 1994) y uno de los actores políticos más relevantes del siglo XX (Hobsbawm, 2007a). En la medida en que el movimiento obrero fue aumentado sus grados de organización y su capacidad para influir en la sociedad, surgieron sindicatos y partidos políticos que bregaban por sus intereses y por la institucionalización de estos en el aparato del Estado (Flacks, 1994). De este modo, se va a producir una fuerte imbricación entre la sociedad, los partidos y el Estado, lo que Manuel Antonio Garretón (2001) denominará matriz clásica o nacionalpopular de la acción colectiva.

Las movilizaciones de la década de 1960 , dan inicio a un segundo periodo en la forma que adquiere la acción colectiva, ya que ponen en evidencia que las demandas, actores y cuerpos teóricos constitutivos de la etapa anterior, quedaban desdibujadas con las tensiones y particularismos expresados por los movimientos feministas, de los derechos civiles, anticolonialistas, pacifistas o ecologistas (Santos, 2001, Wallerstein, 2008).
Johnston, Laraña, \& Gusfield (1994), afirman que estos movimientos presentan articulaciones que no responden a los patrones estructurales. Algunas de las diferencias que plantean estos autores, entre los movimientos que se visibilizan a finales de la década de 1960 con respecto a la acción colectiva de la etapa previa, son (Johnston, Laraña, \& Gusfield, 1994, pp. 6-9):

“[...] no tendrán una relación clara con los roles estructurales de sus seguidores."

"Sus características ideológicas contrastan notablemente con las del movimiento obrero y con la concepción marxista de la ideología, como el elemento unificador y totalizante de la acción colectiva."

"[...] con frecuencia implican el desarrollo de [...] aspectos de la identidad de sus miembros que antes tenían escasa importancia y de aspectos íntimos de la vida humana."

"Difuminación de la relación entre el individuo y el grupo."

"[Se relacionan] con la crisis de credibilidad de los causes convencionales para la participación en la vida pública de las democracias occidentales."

"En contraste con las estructuras de cuadros y las centralizadas burocracias de partidos de masas tradicionales, la organización de los nuevos movimientos sociales tiende a ser difusa y descentralizada."

A partir de esta década, se produce una separación cada vez mayor entre la política formal orientada hacia el Estado y el énfasis dado por los actores colectivos a la vida cotidiana ${ }^{3}$ (Castells, 1999; Flacks, 1994).

3 Entre las hipótesis sobre esta transformación de la acción colectiva, destacan las dadas por Inglehart (1991), quien plantea el surgimiento de valores postmateriales en las sociedades industriales avanzadas y la de Habermas, quien afirma que los movimientos sociales intentan resistir, desde el mundo de la vida, a su colonización total por parte del sistema socioeconómico (citado en Calhoun, 2002). 
En lo que respecta a Chile, los sujetos colectivos estarán íntimamente ligados a la matriz clásica hasta los gobiernos postautoritarios (Garretón, 2001). A partir de los gobiernos de la Concertación de Partidos por la Democracia ${ }^{4}$ y, pese a algunas movilizaciones puntuales de movimientos ecologistas, obreros, estudiantiles, de minorías sexuales e indígenas, se produce un repliegue de la acción colectiva pública de los movimientos sociales. Tras la pérdida de centralidad de la matriz nacional popular y de los partidos políticos, la acción colectiva tenderá a orientarse hacia "actores definidos socioculturalmente y por referencia a los mundos de vida (subjetividad)" (Garretón, 2001, p.40). Replicando, con ciertos matices, lo acontecido en otros lugares del planeta.

De este modo, los partidos políticos y la figura del Estado se irán convirtiendo en "caparazones vacíos, cada vez menos capaces de relacionarse con la vida y con los valores de la gente en la mayoría de las sociedades" (Castells, 1999, p.394). Concomitantemente, el hecho de que los movimientos sociales se fragmenten en colectivos con identidades particulares, traerá como consecuencia la pérdida de proyectos más generales entre ellos (Castells, 1999; Wagner, 2013).

No obstante, el hecho de que una parte importante de la acción colectiva contemporánea se produce y reproduce en la dimensión cultural de las sociedades, las investigaciones que versan sobre ella, tienden a plantearse en torno a la centralidad del Estado y de los partidos políticos abandonando aquellos aspectos relacionados con la cultura (Calhoun, 2002). Asimismo, la mayor parte de la investigación que intentan abordar la dimensión cultural, han optado por hacerlo sobre la movilización (Cefaï, 2009, 2011;
Paredes, 2013) y/o sobre los marcos cognitivos (Chihu, 1999; Gamson \& Meyer, 1999; Hunt, Benford, \& Snow, 1994), de tal forma que el espacio donde los actores colectivos desarrollan su cotidianidad, tejen parte de sus redes y logran socializar a otros individuos en su concepción de mundo por medio de sus modos de convivencia, ha quedado como un lugar escasamente visibilizado.

Para encontrar indicios sobre estas transformaciones en un contexto específico -el de las motivaciones medioambientales -, se recurre en este trabajo al fenómeno de los Asentamientos pro Sustentabilidad (ApS) ${ }^{5}$.

\section{Asentamientos pro Sustentabilidad}

Uno de los actores que surgirá en las décadas de 1960 y 1970 como parte del giro cultural en la acción colectiva y los movimientos sociales, será el movimiento ecologista. Este movimiento, tiene entre sus antecedentes las publicaciones "Silent Spring" de Rachel Carson escrita en 1962, "Science and Survival" de Barry Commoner de 1966, "The Population Bomb" de Paul Ehrlich en 1968 que alertan, respectivamente, sobre el envenenamiento por pesticidas, uso de energía nuclear y los riesgos que entraña la sobrepoblación en el planeta (Estenssoro, 2009; Riechmann \& Fernández, 1994), y se visiblizará públicamente con la creación de dos de las organizaciones no gubernamentales más importantes sobre el tema que perduran hasta hoy día Friends of the Earth de 1969 y Greenpeace fundada en $1971 \mathrm{y}$, con la masiva movilización del 22 de abril del año 1970, fecha en que alrededor de 20 millones de personas se manifiestan en EE.UU. para exigir un medio ambiente sano. Como efectos inmediatos de estas movilizaciones, se crea en dicho país la Agencia de Protección Ambiental y en el

4 Coalición de partidos políticos de centro y de centro izquierda que gobernó Chile entre los años 1990 y 2010.

5 Como sostiene Blaitt "El objetivo de sustentabilidad, es un ideal abiertamente difícil de cumplir y que ninguna comunidad intencional parece haber logrado hasta ahora" (2010, p. 17), debido a esto, se ha preferido ubicar el prefijo "pro" antes de sustentabilidad, tal como lo hace la autora referida. 
plano internacional se convoca a la primera Conferencia de Naciones Unidas sobre el Medio Ambiente realizada en Estocolmo el año 1972 (Estenssoro, 2009; Federovisky, 2011).

El mismo año se publica el primer informe del Club de Roma, titulado "The Limits of Growth" preparado por D. \& D. Meadows y J. Randers, en el que se advierte sobre la conveniencia de detener el crecimiento económico por la amenaza que supone para la vida en la Tierra (Riechmann \& Fernández, 1994).

La preocupación medioambiental toma nuevos bríos el año 1987 con la Comisión Mundial de Medio Ambiente, denominada la Comisión Bruntland, en referencia a su directora, la Primera Ministra Noruega Gro Harlem Bruntland, y su Informe "Nuestro Futuro Común" en el que se delinea la noción de Desarrollo Sustentable que es definido como "el desarrollo que satisface las necesidades de la generación presente sin comprometer la capacidad de las generaciones futuras para satisfacer sus propias necesidades" Comisión Mundial del Medio Ambiente y del Desarrollo, (Estenssoro, 2009, p.111).

Durante las siguientes décadas los foros internacionales, la conflictividad local y las acciones colectivas relacionadas a estas temáticas se fueron incrementado. De forma tal, que las cuestiones vinculadas a la naturaleza, el medio ambiente, la ecología y la sustentabilidad adquirieron creciente influencia en los debates públicos y en las acciones privadas alrededor del mundo.

Una parte del ecologismo, se imbricará con las tradiciones de las colonias utópicas del siglo XIX y de las comunas contraculturales de la década de 1960, para dar origen a una serie de asentamientos que sostienen discursos medioambientales, entre los más conocidos están las ecoaldeas, las comunidades ecológicas y el neorruralimo. Las ecoaldeas, según Robert Gilman, corresponden a "un asentamiento humano, concebido a escala humana, que incluye todos los aspectos importantes para la vida, integrándolos respetuosamente en el entorno natural, que apoya formas saludables de desarrollo y que puede persistir indefinidamente" (Pereira, 2011, p. 32); mientras que las comunidades intencionales implican "un grupo de personas que han optado por vivir juntas o lo suficientemente cerca entre sí para llevar a cabo un estilo de vida compartido o propósito comunes" (Christian, 2003, p. xvi), definición a la que la autora aludida agrega el adjetivo de ecológicas para diferenciarlas de otros tipos de comunidades intencionales, que en su mayoría corresponden a comunidades religiosas. Por su parte, el neorruralismo ha sido definido como un "fenómeno de instalación en el campo de un colectivo mayoritariamente joven y procedente de zonas urbanas" (Nogué, 1988, p.145).

Debido a que estos conceptos son dificilmente operacionalizables a la realidad empírica chilena o como en el caso del neorruralismo, que excluye las manifestaciones urbanas del fenómeno y pone el acento en cuestiones migratorias que no necesariamente abarcan lo medioambiental, se ha preferido hablar de Asentamiento pro Sustentabilidad, entendiendo por tal, a aquel asentamiento cuyos habitantes buscan de modo explícito desarrollar en el territorio formas de vida que tiendan a disminuir el impacto negativo en los ecosistemas y a aumentar paralelamente su impacto positivo en ellos ${ }^{7}$.

6 Según Porto-Gonçalves (2001), la noción de Desarrollo Sustentable, integra como telón de fondo la expansión capitalista de los procesos productivos pero de una forma "amigable" con el entorno medioambiental, como consecuencia, dicha noción permite un rescate del imaginario del desarrollo ilimitado.

7 Desde luego, no se está afirmando que los asentamientos sean o no sustentables, ni tampoco es el objetivo de este artículo abordar los distintos significados asignados a esta noción, sino que, el hecho de que se declaren a favor de ello, se utiliza como un criterio de inclusión del conjunto de casos al cual hacemos referencia. 
A nivel mundial, el fenómeno de los asentamintos pro sustentabilidad, está relativamente extendido, Meijering (2012) contabilizó el año 2003, 473 comunidades intencionales ecológicas en Europa; en Australia, Miller \& Bentley (2012), señalan que el año 2011 existían 15 ecoaldeas registradas en el EcoDirectory; Ergas (2010), afirma que entre los años 1990 y 2007, se pasó de 8 a 900 asentamientos de este tipo inscritos en el Communities Directory de EE.UU. Dawson (2013), señala que al año de su publicación los mayores grupos de comunidades intencionales asociados a la Global Ecovillage Network ${ }^{8}$ (GEN), son Sardovaya con 2000 comunidades ubicadas principalmente en Sri Lanka; COLUFIFA, red de 250 comunidades emplazadas en Guinea, Guinea-Bissau, Senegal y Gambia; y, GEN Senegal con 30 comunidades en dicho país.

En el caso chileno y en un catastro de elaboración propia efectuado el año 2014 (figura 1), se contabilizaron 43 de estos asentamientos. Según afirma Ergas (2010), este fenómeno ha aumentado su presencia a escala mundial durante las últimas décadas, cuestión que coincide con nuestras cifras. En efecto, entre los años 2004 y 2014, se incrementó su presencia en Chile en 37 asentamientos, es decir, tuvo un aumento de un $86 \%$ (figura 2) ${ }^{9}$, lo que evidencia una complejidad creciente durante los últimos
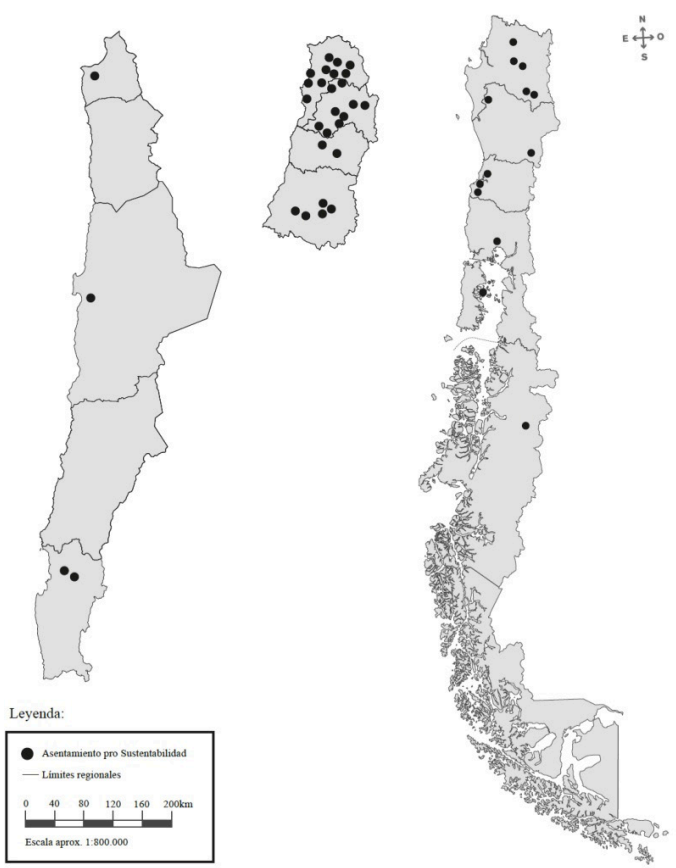

Figura 1. Ubicación de los Asentamientos pro Sustentabilidad en Chile. Fuente: Elaboración propia efectuada en base a entrevistas con informantes privilegiados e información digital, 2014.

Figure 1. Location of the Pro-sustainability settlements in Chile. Source: Own elaboration effected based on interviews with privileged informants and digital information, 2014.

8 Ver: http://gen.ecovillage.org/es

9 Catastro de elaboración propia basado en los ApS existentes hasta el año 2014 en Chile. Los datos se obtuvieron a través de información digital en la cual se explicitaba el año de origen; en la ausencia de esta información, se optó situar la fecha de origen a la primera información pública recabada o referida, con excepción de cinco casos en que la información fue suministrada por informantes privilegiados. 


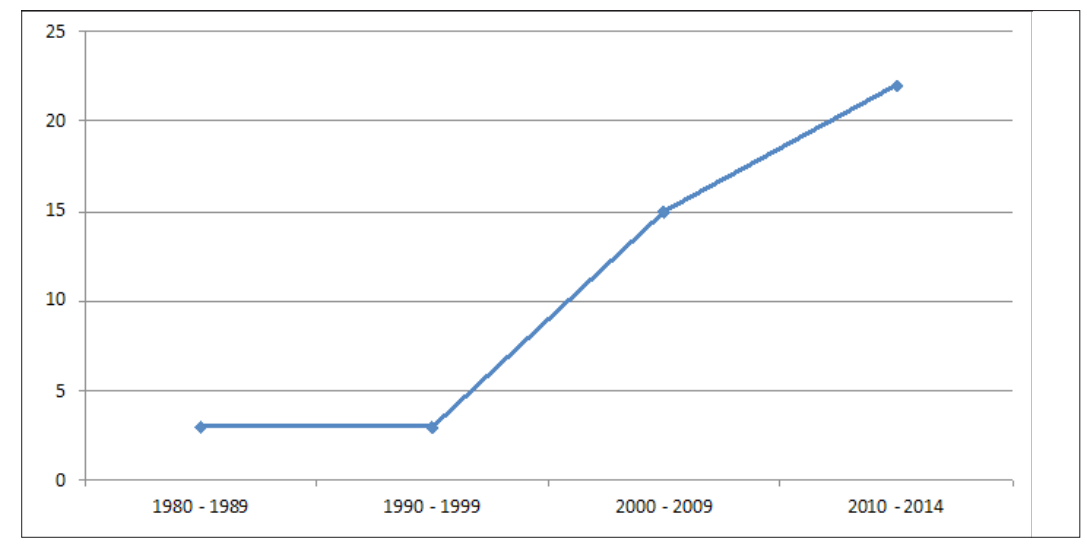

Figura 2. Asentamientos pro sustentabilidad en Chile por periodo de origen. Fuente: Elaboración propia en base a información digital y entrevistas, 2018.

Figure 2. Pro-sustainability settlements in Chile by period of origin. Source: Own elaboration based on digital information and interviews, 2018.

años, tanto en el número de asentamientos, como en la densidad de la red y el número de participantes. No obstante esto, la cantidad de estos proyectos que fracasan durante los primeros tres años oscila entre un $75 \%$ y un 90\% (Christian, 2003).

Al analizar su distribución geográfica, es posible plantear que los ApS se distribuyen en Chile del siguiente modo: cuatro, en las zonas centro norte y norte; 26 , en la zona central y 13 , en el centro sur y sur del país; tal como se resume en la tabla 1. Es probable que su predominancia en la zona central se deba a las condiciones climáticas en las cuales se insertan. En condiciones climáticas adversas, tales como la alta montaña, zonas desérticas o extremadamente australes, se dificulta la habitabilidad humana, con mayor razón, cuando se intenta experimentar con técnicas de construcción o de cultivos, dimensiones centrales para la constitución de ApS.

Territorialización e imaginario colectivo.

Los autores coinciden, que entre los motivos que llevan a los individuos a formar parte de un ApS, está el rechazo hacia el hacinamiento, polución, congestión, vínculos interpersonales y seguridad de las grandes ciudades (Hidalgo \& Zunino, 2012; Pereira, 2013; Zunino \& Hidalgo, 2010).

No es casual, la ciudad contemporánea se transforma en una de las manifestaciones más elocuentes del capitalismo avanzado, debido a que éste requiere para su expansión de la producción de un mercado inmobiliario y financiero relacionado (Harvey \& Fernández, 2011). De tal modo, que la ciudad se transforma en un espacio colonizado por el mercado, este dibuja sus formas, establece los lugares por donde las personas se movilizan y el escenario que será presenciado por la mayor parte de los habitantes del mundo (Debord, 1995). Frente a esto, surgen colectivos que expresan la intención de disputar las decisiones sobre el territorio en el que conviven (Canteros, 2011) o, como el caso que nos ocupa, construir de otra forma el imaginario de la vida anhelada.

Este imaginario, contiene un mundo de significaciones que se materializan en el territorio al que se arriba (Berger \& Luckmann, 1967; De Certeau, 1990; Giannini, 1999). Dicha materialización, implica un proceso de sedimentación 
de sus prácticas colectivas que recibe la denominación de territorialización (Escobar, 2000; Fernandes, 2005; Oslender, 2010; Porto-Gonçalves, 2001).

De este modo, acceder al imaginario de un colectivo que se territorializa, conlleva identificar el conjunto de prácticas y significaciones que este privilegia dentro del magma de significaciones sociales en el cual se encuentra inserto (Cancino, 2011, 2015). Este imaginario, recibirá las influencias de los imaginarios predominantes de la sociedad; $\mathrm{y}$, simultáneamente, incidirá en ellos, disputando y alterando el magma social del que forma parte (Arribas, 2008). Es este proceso de alteración o transformación de los imaginarios de la sociedad que portan los actores emergentes, el que dará indicios sobre la acción colectiva actual. Señalado lo anterior, el problema que interroga este texto refiere a las formas que adquiere la acción colectiva contemporánea en un contexto de motivaciones medioambientales.

\section{Materiales y métodos}

\section{Movimientos sociales: de la estructura de clases a la red sumergida}

El origen de la expresión movimiento social se encuentra imbricado a la emergencia de dos procesos simultáneos, la Revolución Industrial y la Revolución Francesa. La concomitancia de ambos procesos, y en clave marxista, la modificación de las relaciones de producción, generarán las condiciones para la emergencia del proletariado, de la clase obrera $\mathrm{y}$, posteriormente, del movimiento obrero. A este respecto, Hobsbawm (2007b, p.233), señala: "La era del capitalismo floreciente y estable ofrecía a la clase obrera la posibilidad de mejorar su suerte mediante la organización colectiva". Mediante su organización, el proletariado aumentará su influencia en el aparato del estado por medio de la ampliación del electorado a fines del siglo XIX y comienzos del siglo XX (Hobsbawm, 2007a). En consecuencia, la clase y el movimiento obrero se configuran en una categoría central para interpretar el modo en que la sociedad se estaba estructurando. En este contexto, y debido a la censura que recaía sobre los movimientos socialista y comunista, Lorenz von Stein acuña en 1850 el eufemismo "movimiento social" para aludir a la clase obrera que adquiere conciencia de sí misma (Pérez, 1994; Tilly \& Wood, 2010).

Hasta la década de 1960, su utilización no había variado de forma sustancial y continuaba siendo común referirse por movimiento social al movimiento obrero y por extensión a algunas otras formas de acción colectiva relacionadas con la estructura de clase (Johnston et al., 1994). Las movilizaciones que acontecen en dicha década, ponen en evidencia la emergencia de demandas y actores colectivos que no cabían necesariamente en la estructura de clase: jóvenes, mujeres, diversidades étnicas y sexuales, nacionalismo, anticolonialismo, pacifismo, entre otros, permeabilizan el escenario sociopolítico en coexistencia con las formas clásicas de movimientos sociales. Estos actores se movilizaron en contra de "formas de opresión que sobrepasan las relaciones de producción" (Santos, 2001, p.178); desconfiando del Estado, así como de la acción orientada hacia el mismo (Wallerstein, 2008).

Estas transformaciones en la acción colectiva requirieron de un giro teórico para su análisis. Uno de sus precursores, Alain Touraine $(1994,1997)$ afirmó que en la sociedad postindustrial se transita desde el conflicto económico y político al conflicto cultural; de este modo, la disputa de los movimientos sociales estará dada por los valores que orientan a la sociedad (Touraine, 1997). Los planteamientos de Touraine implicaron que el uso de la noción de movimiento social se amplió desde su aplicación a actores dentro de la estructura de clase a actores colectivos diversos que bregaban por transformaciones culturales. 
El siguiente impulso hacia la ampliación del uso de la noción de movimiento social vino de la mano de Alberto Melucci, quien, en sus indagaciones sobre movimientos ecologistas, de mujeres, jóvenes, de minorías étnicas y nacionales, desarrolladas en el norte de Italia, entre 1979 y 1983 (Melucci, 1983), descubre una serie de grupos y organizaciones que sirven como condición a las movilizaciones y la acción visible de los movimientos (Mueller, 1994). Melucci (1994a), señaló que estos grupos operan como redes sumergidas y que sirven de laboratorios de experimentación cotidianos a través de los cuales se disputan los códigos culturales dominantes de la sociedad; dichas redes, permiten a los individuos la elaboración de significados con los que se promueven cambios sociales, a la vez que facilitan la creación de identidades colectivas.

Desde los desarrollos teóricos de Melucci (1994a, 1994b), la noción de movimiento social, no solo se va a referir a la acción visible y mensurable de los mismos, sino que también incluirá a sus redes sumergidas e interacciones cotidianas. Esto implica que un movimiento social no puede ser reducido a un aspecto en particular del mismo, como por ejemplo, una manifestación o protesta pública, ya que éste hecho estará inserto en un proceso social más amplio, en el que convergen diferentes aspectos. Asimismo, dejarán de concebirse como un todo homogéneo, por el contrario, se observará en ellos una pluralidad de organizaciones, grupos e individuos que se ubican en diferentes posiciones respecto al movimiento y los conflictos que lo atraviesan.

Esta forma de entender a los movimiento sociales, permite observar en la cotidianidad de los actores, en sus redes, prácticas y significados, los momentos en que se oponen y entrelazan, lo contencioso y lo no contencioso, la micro y la macropolítica (Foucault, 1993; Weber, 1995). Del mismo modo, facilitan las comprensión de las formas de socialización política, en un contexto distinto a la forma partido que primó durante buena parte del siglo XX.

\section{El giro territorial en el estudio de los movimientos sociales.}

En América Latina, han emergido una serie de movimientos sociales de carácter territorial que expresan diferentes tensiones contemporáneas. Entre otros, se pueden observar a los movimientos de pobladores que conflictúan el acceso a la vivienda (Garcés, 2002); los movimientos indígenas de Ecuador, Perú, Bolivia y Chile, que ponen en evidencia la discriminación racial y la demanda por autonomía territorial (Bengoa, 2007; García, 2012; Pinto, Candina, \& Lira, 1999; Piñeiro, 2004); el MST y el MZLN, que bregarán en contra de la desigual distribución en la propiedad de la tierra (Le Bot, 2009; López, 1999; Fernandes, 2008); o, las agrupaciones vecinales que se manifiestan por la defensa de los barrios (Canteros, 2011).

Debido a esto, se ha ido configurando un ámbito de estudio que aborda la territorialidad ligada de estos actores colectivos como una temática central. En nuestro caso, existen dos dimensiones particularmente relevantes que se inscriben y son producidas por la dinámica territorial, estas son: los procesos de territorialización y desterritorialización; y, entrelazadas con éstas, las significaciones y las prácticas colectivas que estas expresan.

Bernardo Fernandes siguiendo a Lefevbre, afirma que, "el territorio es el espacio apropiado por una determinada relación social que lo produce y lo mantiene a partir de una forma de poder" (Fernandes, 2005, p. 27). El territorio, puede ser continuo o discontinuo y con diferentes escalas. Asimismo, experimenta modificaciones de distinto orden denominadas procesos geográficos, dentro de las cuales destacan, la territorialización y la desterritorialización. La primera, se manifiesta como expansión 
y creación de territorios; la segunda en cambio, lo hace como reflujo y destrucción del territorio. Ambas, conllevan la producción de acciones investidas de sentido e implican la modificación de sus relaciones sociales previas. De tal forma, que los movimientos socioterritoriales transforman espacios sociales en territorios, cuestión que pueden hacer de modo fragmentado, en una microregión; o bien, conformando una red de relaciones a través de las cuales promueven y fomentan la territorialización (Fernandes, 2005).

En un sentido similar, Porto-Gonçalves (2001, p.17) señala que se debe "desnaturalizar el concepto de territorio y percibir que en él subyace una territorialidad que se instituye, es decir, existe un proceso de territorialización". Este proceso, será posible de observar a través de las prácticas, dado que estas, son instituidas por los colectivos humanos por medio de los sentidos que estos les atribuyen. En consecuencia, las prácticas, son producidas y a la vez reproducen formas de conocimiento situadas, dinámicas y simbólicas, que mantendrán una relación dialéctica con las representaciones dominantes del espacio, siendo permeadas por éstas y a la vez, resistidas (Oslender, 2010).

En las prácticas locales y en el conocimiento arraigado en ellas, se pueden ubicar una variedad de formas en que lo cultural se convierte en política (Escobar, 2000). Permitiendo con ello, la emergencia de procesos identitarios mediante los cuales los individuos reconocen sensibilidades similares y, la ampliación por parte de los activistas, de sus bases de apoyo, vínculos y redes (Castells, 2012).

Las prácticas y las significaciones que las invisten, se entrelazan y conforman múltiples territorialidades (PortoGonçalves, 2001, 2008). Con el propósito de indagar en ellas, se recurrirá a la noción de imaginario colectivo.

\section{Del imaginario social al imaginario colectivo}

La noción de imaginario colectivo se desprende de las de imaginario social y de magma de significaciones sociales de Cornelius Castoriadis, por lo que es necesario referirse a estas brevemente. Para Castoriadis (2007), el imaginario social, alude al conjunto de instituciones y significaciones encarnadas en ellas, a través de las cuales las distintas sociedades se dotan de existencia. Por magma de significaciones sociales, Castoriadis (2005), va a distinguir una de las dimensiones del imaginario social, la que hace referencia a la totalidad de significaciones que existen en una sociedad.

El magma no es estático, en su interior ocurren modificaciones, disputas y hegemonías. A este respecto, Sonia Arribas (2008, p.106), sostiene que "La sociedad no es simple agregación de individuos o de sus interacciones; es una red cambiante de significados que configura modos de comportamiento y creencias". Parte de estas modificaciones son aquellas impulsadas por la acción colectiva (Castoriadis, 2002).

Los colectivos humanos tienen la capacidad de materializar sus significaciones a través de las prácticas instituidas, lo que Castoriadis (1998; 2007) denomina de imaginario social instituyente. El imaginario social instituyente será entonces, aquella capacidad de crear o promover prácticas que se van instituyendo por medio de los procesos sociales, a medida que estas prácticas se instituyen, condicionan las creaciones siguientes, socializan a los individuos en ellas y les otorgan sentido de realidad (Castoriadis, 2002, 2005).

Señalado lo anterior, se entiende por imaginario colectivo al conjunto de prácticas y significaciones privilegiadas por un grupo en particular dentro magma social del cual forma parte (Cancino, 2015). Este imaginario, se verá influenciado por 
los imaginarios dominantes en los cuales se encuentra inserto y podrá disputar y/o articular instituciones y significaciones con otras grupalidades (Cancino, 2011).

Siguiendo a Lizcano (2003, p.10), existen dos riesgos en la operacionalización de la noción de imaginario social, ellos son: la tendencia a ignorar las hibridaciones y préstamos entre los distintos imaginarios, concibiéndolos de modo fragmentario y con homogeneidad interna; y la esencialización de "configuraciones arquetípicas eternas y universales", a través de las cuales se pierden las diferencias de cada caso en particular. En razón de ello, se entiende que el imaginario colectivo expresa la configuración cultural de una grupalidad en particular abarcando tanto sus tensiones internas como las que se producen con el imaginario social dominante en el que está inserto. Asimismo, la noción de imaginario colectivo sugiere ingresar al fenómeno indagado por la vía de sus instituciones imaginarias sociales o prácticas colectivas, a partir de las cuales, se profundiza en el universo de significaciones que las animan. Integrando con ello, tanto sus dimensiones materiales como las simbólicas.

En consecuencia, la noción de imaginario colectivo imbrica cuestiones epistemológicas, teóricas y metodológicas. En palabras de Moreno \& Rovira (2009, p.32), trasciende lo abstracto para "entablar una relación directa con el trabajo empírico".

\section{Métodos}

Durante la fase exploratoria de esta investigación, mientras se realizaba el catastro y se diseñaban los instrumentos de observación, se visitaron 8 asentamientos, con una duración de 10 días en promedio.
Esta información, además de la de carácter académico con que se contaba hasta entonces sobre el caso en Chile (Concha, 2010; Hidalgo \& Zunino, 2012; Pereira, 2011, 2013; Zunino \& Hidalgo, 2010), se utilizó para determinar cuatro criterios que, combinados, sirvieran para seleccionar un número reducido de asentamientos a ser etnografiados y, junto con ello, permitieran abarcar una pluralidad de experiencias. Estos criterios fueron zona bioclimática, número de habitantes, antigüedad del asentamiento y tipo de propiedad. De este modo, se buscó combinar asentamientos que se encontraran en dos o más tipos de zonas bioclimáticas; que, al menos dos tuvieran diferencias significativas en la cantidad de habitantes y en su antigüedad; $y$, que la vinculación a la propiedad de la tierra fuera de dos o más formas. A los criterios de selección anteriores, se debe agregar la disposición de los habitantes o de parte de ellos en el asentamiento de mayor tamaño, a participar de la investigación.

Los asentamientos seleccionados para la etapa final de la investigación fueron, la Ecoaldea Pailimay ubicada en la VI región ${ }^{10}$ $\mathrm{y}$ las comunidades Blowing in the Wind y Piuke Ko en la $\mathrm{V}$ región. Tal como lo expresa la tabla 1, la Ecoaldea Pailimay tuvo su origen el año 2011, se emplaza en una zona bioclimática precordillerana y rural, la habitan 12 personas entre adultos y niños, los adultos son copropietarios del terreno junto a otros copropietarios no habitantes; en el caso de Blowing in the wind, tuvo su origen el año 1985, en lo que en ese entonces era una zona rural y costera, en la actualidad quedó inmersa en una zona periurbana de alta plusvalía, entre las ciudades de Reñaca y Concón, este asentamiento tiene 200 habitantes aproximadamente, la mayor parte de los cuales son copropietarios, mientras un menor número corresponde a arrendatarios;

10 Durante la inmersión etnográfica en Pailimay, se asistió por 10 días al Eco Centro Minga Alegre ubicado en Coyahique, debido a que en el transcurso del terreno, la totalidad de los habitantes de Pailimay decidieron acudir al Encuentro de la Red EcoChile celebrado en dicho lugar. Este hecho, permitió observar las actividades organizadas por seis ApS y acceder, al que hasta la fecha, era el ApS más austral del país 
por su parte, la Comunidad Piuke Ko, se fundó el año 2011 en un sector costero, a orillas del Humedal El Criquet, y a pocos metros del cruce La pólvora en las afueras de Valparaíso, entre una instalación militar, un lugar de acopio de containers y una autopista, al momento de efectuar la etnografía tenía cinco habitantes, los que se encuentran desprovistos de algún vínculo legal sobre el lugar, por lo que se podría denominar su situción como de ocupación irregular o toma de terreno. El cruce entre cada asentamiento y los distintos criterios para su selección (tabla 1).

Tabla 1

Criterios en la selección de los ApS etnografiados. Fuente: Elaboración propia, 2018.

Table 1

Criteria in the selection of the researched settlements. Source: Own elaboration, 2018.

\begin{tabular}{llll}
\hline & Blowing in the wind & Pailimay & Piuke ko \\
\hline Zona bioclimática & Costa & Pre cordillera & Costa \\
N $^{\circ}$ habitantes & 200 aprox. & 12 & 5 \\
Antigüedad & 1985 & 2011 & 2011 \\
Propiedad & Propietarios / arriendatarios & Propietarios & Ocupación \\
\hline
\end{tabular}

Debido a que esta investigación interrogó la forma que adquiere la acción colectiva contemporánea en un contexto de motivaciones medioambientales, se optó por efectuar una inmersión etnográfica (Albertín \& Íñiguez, 2010; Auyero, 2000; Geertz, 2006; Guber, 2011), que permitiera identificar el conjunto de prácticas colectivas y significaciones sociales recurrentes efectuadas en dos o más asentamientos. Esta técnica implica sumergirse en los asentamientos para experimentar y compartir su vida cotidiana, guardando registro a través de notas de campo y otros soportes, tales como fotografías o videos, para su posterior análisis (Ameigeiras, 2006; Kawulich, 2005; Taylor \& Bogdan, 1992). De esta forma, se buscó una aproximación a las situaciones cotidianas desde el punto de vista de los actores. Lo que implica "situarnos en la posición y en el conjunto de relaciones desde las cuales las prácticas, las evaluaciones y las creencias [del colectivo] ${ }^{11}$ son construidas e intentar entenderlas desde esta ubicación" (Auyero,
2000, p.189), permitiendo, de este modo, una descripción detallada del "trabajo de auto producción colectiva" (Wacquant, 1997, p.347).

Cada asentamiento se visitó en promedio por 30 días. A través de una observación participante y la producción de 3 cuadernos de campo, fueron identificadas 15 prácticas; mientras que, por medio de 16 entrevistas efectuadas a habitantes de los tres asentamientos, que incluyó a siete mujeres y nueve hombres, con un promedio de edad de 37 años, se identificó un conjunto de significaciones asociadas a cada práctica

\section{Resultados}

\section{ApS, como proceso de territorialización}

A partir del surgimiento de cada uno de los ApS indagados, se fueron agregado con el tiempo otros habitantes, propietarios o proyectos que también sostienen discursos en pro de la sustentabilidad y

11 Clientelares en el origina 
de la naturaleza, ampliándose con ello, aproximadamente al doble el tamaño original de cada asentamiento. De este modo, lugares que previamente habían sido intervenidos con plantaciones forestales, dan inicio a un proceso de territorialización, a través del cual, son resignificados como una zona de protección, recuperación o resistencia ambiental; simultáneamente, son dotados de infraestructura y prácticas cotidianas que expresan de modo material, el imaginario colectivo de sus habitantes.

Se han seleccionado 5 prácticas colectivas y las significaciones asignadas a la naturaleza que se encuentran a la base de cada una de estas prácticas, ya que permiten dar luces sobre el objetivo trazado en este artículo. Cabe agregar, que los cuadernos de campo se citan: C1, para Pailimay; C2, en eferencia a Blowing; y, C3 para Piuke Ko. Mientras que las citas a las entrevistas han sido etiquetadas con los nombres de pila o con seudónimo, según lo expresado explícitamente por los entrevistados a través del consentimiento informado.

\section{Bioconstrucción}

Al visitar por primera vez los asentamientos en que se iba a realizar el trabajo de campo, era posible reconocerlos por un tipo de construcción característico. Se trataba de edificaciones que contaban con muros de tierra, grandes troncos o trozos de madera, botellas de colores incrustadas en las paredes y otros tipos de material reciclado, en los cimientos, ventanas u otras partes de las construcciones. En efecto, la totalidad de las casas visitadas fueron construidas bajos estas premisas y con estéticas, hasta cierto punto similares.

Debido a que el ingreso en cada asentamiento fue en el rol de voluntario, iba dispuesto a integrarme en las tareas en que se encontraban abocados mis anfitriones, fueron variadas las veces en que participé en algunas actividades relacionadas con la bioconstrucción. La recolección de materiales; elaboración de barro; picar y harnear tierra; construcción de muros, cimientos, baño $\operatorname{seco}^{12}$, pisos y un techo; fueron parte de estas actividades.

De este modo y a partir del trabajo de campo, fue posible entender a la bioconstrucción como un conjunto de técnicas de edificación que promueven la disminución del impacto negativo en los ecosistemas junto al aprovechamiento eficiente de los recursos disponibles en el lugar o en sus proximidades. De los recursos que se emplean, los principales suelen ser la auto construcción, es decir, la mano de obra de los propietarios y la ayuda prestada por voluntarios que, de este modo, reciben conocimientos para emprender sus propios proyectos; el resto de recursos o materiales provienen por lo general del entorno en que se emplaza la edificación - madera de árboles caídos o de manejo sustentable de bosques, rocas, piedras, tierra, arena, paja, coligües, entre otros - o, del reciclaje de desechos (a modo de ejemplo, plásticos, neumáticos, envases).

Dentro de estos materiales, la construcción con tierra, barro o barbotina, ocupa un lugar destacado. Tanto los muros de las casas e inclusive, uno de los techos, estaban siendo construidos con este material. Entre las razones para optar por él, estaba el hecho de que se podía encontrar en abundancia en el mismo terreno o en sus sectores adyacentes, a la consideración de que la tierra es un acumulador térmico $\mathrm{y}$, a la creencia generalizada de que es mejor aislante y con menor impacto medioambiental que el cemento.

Un tipo de edificación construida total o parcialmente bajo las orientaciones de

12 Es un tipo de baño usual en los ApS, que funciona separando los desechos líquidos de los sólidos para no generar malos olores y, paralelamente, producir abono. 
la bioconstrucción, son los domos ${ }^{13}$. En Pailimay, la primera casa que se construyó, está conformada por un domo central, que se ha ido ampliando progresivamente. Para sus cimientos, se han ocupado principalmente neumáticos reciclados $\mathrm{y}$ súper adobe ${ }^{14}$. Los troncos de cipreses muertos o pinos, que sirven de pilares y vigas, han sido recolectados desde la ecoaldea o sus alrededores. Una pequeña parte de la estructura de los muros es de malla acma o de madera elaborada; la mayor parte, es de barbotina entrelazada y de botellas plásticas rellenas con bolsas o envases plásticos, denominados ecoladrillos. Los tragaluces y ventanas, son de botellas, tapas de ollas, parabrisas, entre otros materiales traslúcidos. El proceso de construcción de esta vivienda ha tomado alrededor de seis años y es probable que continúe varios años más debido a que las edificaciones bajo estas premisas son consideradas construcciones vivas, es decir, que se van edificando y modificando de manera cotidiana. Han participado en su construcción, además de los dueños de casa, voluntarios, participantes de los cursos $\mathrm{y}$ dos vecinos que han sido contratados ocasionalmente como trabajadores.

Es usual que la bioconstrucción esté asociada al bioclimatismo, que implica el estudio del terreno, sus caídas de agua, viento e ingreso de luz solar, para adaptar las construcciones al entorno específico en el cual se emplazará y así dotarla de un mayor rendimiento energético. Por esta razón, se tiende a zonificar los asentamientos de tal modo que los desniveles favorezcan la irrigación de los huertos o la instalación de baños secos; que los árboles que se plantan protejan del viento o que las casas estén orientadas de tal forma que permitan el mayor provecho de la energía solar para su calefacción y ventilación. Un ejemplo esto, se puede observar en el siguiente extracto de entrevista:

Necesitamos que sea una casa sustentable. [Explícame un poco eso, ¿cómo va a funcionar?, ¿cómo la están construyendo?] Estamos construyendo una casa de forma rectangular [...] con un dormitorio al lado del otro, [...] cada salida de este dormitorio va a dar a un jardín interior que es un invernadero. Un invernadero [que nos brindará] el calor necesario para el invierno y la frescura necesaria para el verano. [En el invierno] que es cuando más necesitamos el calor del sol para no tener que usar tanta calefacción en leña, que nos llegue el sol. La casa tiene los ventanales del invernadero con una inclinación lo cual permite que el sol nos llegué durante todo el día. Desde las 9 de la mañana que es cuando está saliendo acá, porque nosotros hicimos como ese estudio, fuimos a esperar el sol este mes para ver a qué hora empezaba a alumbrar, de las 9 de la mañana hasta las 6 de la tarde, para que pueda entibiarse durante todo el día y conserve el calor durante la noche. El invernadero tiene una altura en la cual te permite tener árboles dentro. [...] necesitamos plantar árboles [...] que sean caducos, que en verano den hojas y sus frutos pero que en invierno y el otoño boten sus hojas; entonces en el [verano] van a cubrir el invernadero por dentro y van a recibir los árboles y las hortalizas el calor, el exceso de calor que entraría

13 El domo es un diseño de construcción semicircular, habitualmente se utiliza tabiquería de madera o PVC que, al unirlas, producen una serie de triángulos y pentágonos que conforman la estructura de la edificación. En los cimientos, suelen utilizarse neumáticos reciclados; sacos con tierra denominados súper adobe o bien, si la estructura es liviana, una plataforma tipo palafito. Los domos de Pailimay, estaban cubiertos en algunos casos por lonas de PVC y en otros casos por tierra (barbotina).

14 Se le llama súper adobe, a sacos de alrededor de 50 kilos que son llenados con tierra harneada. Los sacos se ponen uno al lado del otro hasta completar el perímetro de la construcción y luego, se replica el mismo perímetro en sucesivos niveles para darle la altura requerida. Habitualmente se ocupan tres niveles para los cimientos. En algunos diseños, se ocupa súper adobe para la construcción de muros. 
a los dormitorios. Y en invierno, como caducan, entraría el sol que es el que necesitamos para calefaccionar la casa. [...] Este modelo nos permite secar la ropa adentro de la casa en invierno, sin tener la necesidad de estar colgándola [...] arriba de la estufa para que se seque. [...] Las murallas también po, las murallas son más gruesas de lo que hicimos anteriormente. Tiene un grosor más espeso y tiene un baño seco que también da $[\ldots]$ hacia el norte, para que todos los aportes se sequen más rápido y podamos tener un rico compost en menor tiempo. Con dos cámaras queremos hacerlo. [...] Y con techo vivo, entonces la construcción es bien tosca. Es bien firme, porque necesitamos también tener un buen aislamiento en todo sentido, en el techo y en las murallas. [...] Y también con un receptáculo de aguas lluvia. Porque el agua también que cae en el techo arriba, en las plantitas y que va a filtrar, también deseamos guardarlas en un receptáculo. (Tatiana-1-33:45)

Si bien, la bioconstrucción es una de las prácticas más comunes en los $\mathrm{ApS}$, no está ajena a diversos modos de entenderla ni de llevarla a cabo; inclusive, su propia denominación fue objeto de críticas. Esta crítica, apuntaba al poco cuestionamiento y escasa creatividad para reemplazar el uso de materiales industriales. En efecto, fue habitual observar que muchas de estas construcciones se realizaban con maquinarias o herramientas, contaban con cemento o, como en el caso de algunos domos, con madera dimensionada que bien podría provenir de plantaciones forestales. Lo central de este cuestionamiento, planteaba que bajo la moda o la creencia del prefijo "bio", se impactaría negativamente al medio ambiente, pero esta vez, de un modo irreflexivo. A partir de esta crítica, se planteaban dos visiones. La primera, consideraba que se debía priorizar la opción por materiales reciclados $\mathrm{o}$ del lugar y que, dependiendo de las condiciones ambientales, los materiales industriales eran necesarios para mantener la durabilidad de las construcciones.

La segunda visión, sostenía que, dado que la bioconstrucción evitaba un cuestionamiento sobre los materiales industriales e incluso, sobre las condiciones del trabajo, era preferible optar por la construcción natural. En la práctica, esto se traducía en la eliminación de la mayor parte de las herramientas y materiales industriales. De este modo, en vez de motosierra o sierra eléctrica, se prefería el hacha o el serrucho; en vez de clavos, se comenzaba a experimentar con encajes y nudos; se preferían las formas rectas a las curvas debido a que era más simple obtenerlas desde los troncos sin recurrir a otro tipo de tecnología. Quienes optaban por la construcción natural, relataban que recorrían los campos consultando a sus habitantes sobre técnicas preindustriales, este era el caso de Piuke Ko. A modo de ejemplo, parte de los días en que estuve en aquel asentamiento, una de las tareas prioritarias fue impermeabilizar el techo del "chozón", una casa de tres habitaciones y de unos $60 \mathrm{~m} 2$ que estaba en sus últimas fases de edificación. La forma en que esta tarea se estaba llevando a cabo, consistía en cubrir el techo con una capa delgada de revoque grueso; cubierta por otra capa de revoque fino y, sobre esta, una mezcla de aceite y cera de abeja. Según contaban sus habitantes, era primera vez que probaban esta técnica, por lo que todos estábamos a la expectativa de observar cómo se comportaba con las lluvias. No tardó mucho tiempo en llover y pudimos ver que el experimento había funcionado. Meses después fui invitado a la inauguración del chozón y el techo continuaba con su buen funcionamiento.

\section{Cultivos}

Otra de las prácticas comúnmente observadas fueron los cultivos, los que por lo general tomaban la forma de huertos 
edificados en las proximidades de las casas o en las zonas comunitarias de los asentamientos. Su tamaño variaba entre los $4 \mathrm{~m}^{2}$ y $150 \mathrm{~m}^{2}$. Dependiendo de la zona, se sembraban frutales, hortalizas, tuberculos y hierbas medicinales que proveían de una pequeña parte de las necesidades alimenticias de los habitantes.

En caso de que alguno de los cultivos presentara excedentes eran intercambiados por otros alimentos producidos por miembros de las misma comunidad o del exterior. Según señalaron los entrevistados, los cultivos eran efectuados preferentemente de modo orgánico, es decir, excentos de la utilización de semillas o abonos industriales. En el siguiente texto, se puede apreciar la producción de abono.

Durante el desayuno en Pio $\mathrm{Pio}^{15}$, se mencionó que, si queríamos, podíamos ir a Blowing a ayudar a unos muchachos que estaban haciendo una mezcla de tierra y abonos para utilizarlos como fertilizantes. Al poco rato, cruzamos el cerco que separa los terrenos $\mathrm{y}$, junto a otros voluntarios, nos sumamos a la elaboración de un abono llamado bocachi. Las tareas consistieron en llenar sacos de paja y baldes de agua y depositarlos en una mezcla de melaza, gallinazo, tierra, biocultivos y otros ingredientes, que se iban colocando en orden y en varias capas, una y otra vez. Este abono, según nos contaron, estaría listo en un par de semanas y requería que se le revolviera dos veces al día durante ese periodo para bajar su temperatura, de lo contrario, el aumento de la temperatura podía ocasionar que los microorganismos murieran y con ello, el abono perdería buena parte de su potencial. Estuve trabajando ahí unas 4 horas y luego regresé a Pio Pio. (C2, p.6)
Los huertos implican la construcción de bancales, sistemas de regadío, edificación y reparación de cercos, preparación y traslado de tierra fértil y abonos, siembra y cosecha de productos, entre otras tareas; por lo que en su mantención, se tienden a invertir grandes cantidades de trabajo y tiempo, cuestión que se exacerba si, por ejemplo, existe presencia de ganado que los amenace. Fue común que, en diferentes momentos, me correspondiera a mí o a otros voluntarios algunas de estas tareas. De hecho, mientras nos encontrábamos con los habitantes de Pailimay en Coyhaique, en un Encuentro de EcoChile, un voluntario que se había quedado al cuidado de la ecoaldea, llamó por teléfono a una de las habitantes para contarle que las vacas que merodean el sector habían entrado a su huerto y lo habían devastado. Al regresar a Pailamay, durante mi segunda visita, no quedaban más que unos pocos árboles y algunos almácigos. Dado esto, los propietarios de aquel huerto aprovecharon de modificar su diseño para mejorar la circulación del agua y edificar nuevos bancales.

Quizás, debido a la gran cantidad de tiempo y trabajo que demanda la mantención de cultivos, fue común encontrar huertos en estado de abandono o de incipiente recuperación. Lo que sucedía con mayor frecuencia cuando se trataba de cultivos comunitarios. Este hecho, era un indicio o expresión de algo que presencié en la fase exploratoria y luego, en dos de los tres asentamientos visitados. Se trataba de que en los comienzos de los asentamientos, existía la tendencia a poner las energías en lo comunitario y sus espacios. Con el paso del tiempo y en la medida que se iban formando familias; el trabajo y los tiempos, se volcaban hacia ellas y la experiencia comunitaria se iba postergando o, activándose de manera menos recurrente. Asimismo, tanto en la fase exploratoria

15 Pio Pio es un asentamiento vecino a Blowing, donde me alojé y fui recibido como voluntario e investigador para desarrollar el trabajo de campo. Es definido por sus integrantes como un centro cultural que promueve la colaboración y la gestión medioambiental (ver: http://www.piopiochile.org/index.html). 
como en la posterior etapa analítica del trabajo de campo y, a través de conversaciones informales con los residentes, fue posible tomar conocimiento de una discusión común que solía darse al inicio de algunos ApS, esta consistía en la pertinencia de poner o no cercos para proteger los cultivos. Los propietarios residentes preferían poner cercos para alejar a los predadores de los huertos, en desacuerdo con estos, existían propietarios no residentes que, a efectos de mantener el paisaje prístino, preferían no poner cercos. Esto podía llevar a situación de tensión que se tendían a resolver de acuerdo a los intereses de los residentes.

Otra crítica a esta práctica que surgía desde los propios habitantes, tenía que ver con que la cantidad de alimentos producida era inferior a las necesidades calóricas de las familias asentadas. Esto, fue relativamente fácil de corroborar al comparar cuántos alimentos se obtenían desde los huertos y cuántos desde las tiendas o ferias. Por cierto, la relación variaba entre los distintos asentamientos y entre los distintos hogares.

\section{Manejo de plantaciones}

Una práctica ligada a la anterior pero que a su vez se entrelazaba con otras, tales como la obtención de materiales de contrucción o calefacción, era la tala de árboles de pino y eucaliptus, y su reemplazo por especies nativas y frutales.

En los terrenos correspondientes a los tres asentamientos indagados, fue coincidente que, en un periodo previo a su creación, se plantaran una gran cantidad de estas especies exógenas, por lo que sus habitantes, ya sea por pragmatismo, como parte de las prácticas hacia la sustentabilidad o ambas, decidían talarlas. Los árboles de mayor tamaño eran utilizados como pilares y vigas en las contrucciones y los de menor tamaño como leña para hornos de barro, cocinas y estufas. Al mismo tiempo, eran plantados árboles frutales o se favorecía el crecimiento de especies nativas. Estas acciones permitían observar un fuerte contraste entre las especies existentes en cada asentamiento y su entorno, que por lo general, contaba con grandes cantidades de pinos y eucaliptus.

En efecto, en Pailimay, Blowing y Piuke Ko, existían casas construídas en gran parte con troncos obtenidos en el mismo terreno o sus alrededores. Así por ejemplo, las vigas y pilares de la casa de Carolina y Felipe, correspondían a cipreses muertos. En el caso de Blowing, la casa de Elías había sido construida con eucaliptus de los alrededores; en el caso de Piuke Ko, durante una semana, estuve junto a una de las habitantes y a Horacio, cortando y pelando ecucaliptus de aproximadamente 4 metros que luego se ocuparían para montar parte de un techo.

\section{Indigenísmo}

El indigenísmo es considerado una manifestación del proceso de territorialización, debido a que al igual que en los casos anteriores, constituye una práctica colectiva recurrente que se expresa materialmente a través de diversas manifestaciones y a la que se le asignan una pluralidad de sentidos. Contribuyendo de esta forma, a investir el territorio analizado con un cierto tipo de imaginario colectivo. Las temáticas relacionadas a pueblos indígenas fueron uno de los tópicos más frecuentes en las conversaciones, en la exposición y recomendación de videos, libros, músicas y/o lecturas. En todos los asentamientos visitados y en varias de las casas dentro de ellos, fue posible observar banderas mapuches y/o aimaras, adornos y simbología indígena en sus paredes, muros y altares; textos y canciones escritos en mapudungun o en alguna otra lengua indígena. Así, por ejemplo, en una de los asentamientos se participó de una ceremonia de wetripantu ${ }^{16}$, en otro

16 Año nuevo mapuche. 
se observó un ritual a favor de una machi encarcelada y en un tercero, se asistió a un temazcal ${ }^{17}$ y a una charla expuesta por un indígena de origen amazónico.

Aunque las temáticas indígenas podían observarse a simple vista y en todos los asentamientos, no contaban con una valoración común de parte de todos los habitantes. A modo de ejemplo, en uno de los asentamientos podían verse inscripciones indígenas en paredes y puertas de una de las construcciones comunitarias, sin embargo, al conversar sobre estas con los habitantes del lugar, señalaban que las habían pintado visitas del pasado y que ellos hubieran preferido que no las hicieran y simplemente, habían quedado ahí. En el mismo lugar, facilitaban el espacio para hacer temazcales o le prestaban artefactos a quienes se reunían para hacer rogativas por una machi encarcelada, a pesar de que relataban no sentirse identificados con estos discursos.

En efecto, en todos los lugares se pudo constatar que mientras para algunos habitantes lo indígena aparecía como una forma de tradición valorada debido a sus conocimientos y a la atribución de altos grados de armonía con la naturaleza, en otros en cambio, se criticaban los recursos estéticos utilizados para imitar sus prácticas, se ponían en tela de juicio la supuesta armonía con la naturaleza o incluso, los intereses detrás de algunas de sus demandas. Aunque la totalidad concordaba en criticar el trato que recibían estas etnias, particularmente el pueblo mapuche, por parte de los Estados nacionales.

\section{Generación de Redes}

Tanto los ApS de la fase exploratoria como los visitados durante la fase analítica, emergieron como puntos de interjección de distintas redes. A su vez, la participación y generación de redes era un propósito explícito, manifestado por los habitantes en cada uno de los asentamientos. Lo anterior, transformaba a cada ApS en un nodo, que reunía en un territorio específico a personas y grupos con intereses variados, dentro de los cuales destacaban los relacionados con la biconstrucción, los cultivos y la alimentación orgánica, las terapias transpersonales, el indigenismo y el arte. Por cierto, estas redes operaban en distintas escalas y temporalidades. De este modo, se podía apreciar la participación de los ApS en redes globales, nacionales o locales. Asimismo, existían redes que se manifestaban cotidianamente, mientras que otras, lo hacían eventualmente.

Al menos cinco de los asentamientos catastrados y uno de los tres seleccionados para la indagación etnográfica pertenecen a la Red de Ecoaldeas EcoChile y que agrupan a una serie de iniciativas que promueven formas de vida sustentable, esta organización a su vez forma parte de una red de carácter latinoamericano denominada CASA y de la Red Global de Ecoaldeas (GEN por sus siglas en inglés), que es la red mundial de mayor tamaño de este tipo de iniciativas.

Simultáneamente, cada asentamiento, o los habitantes en él, han tejido sus propias redes con otros individuos, agrupaciones y vecinos, con quienes comparten intereses y realizan actividades en conjunto. Dentro de estas, se pueden citar como ejemplos a las reuniones de coordinación que se dan entre Piuke Ko y dos tomas aledañas, denominadas Pueblo Libre y Barrios Bajinos; $y$, la relación que se establece entre Blowing in the wind con los proyectos vecinos Colegio Aldea del Bosque, Pio Pio y Bosque abierto, estos últimos, proyectos pro sustentabilidad que se han ido agregando al primero durante el proceso de territorialización.

17 Ceremonia precolombina que consiste en la toma de un baño de vapor, meditaciones y cantos, y que se desarrolla en el interior de una construcción en forma de domo denominada iñipi. 
A través de la generación de redes, se promueven formas de intercambio que, en gran medida, no están mediadas por el dinero, tales como la minga y el trueque, estableciendo relaciones sociales que operan a través de una suerte de cadena de favores recíprocos y permiten que, con el paso del tiempo, la red se mantenga, extienda y se actualice con cada nuevo favor.

En casos extremos, estas redes funcionan como soporte para desastres u accidentes y eventos contenciosos. Como ejemplos de lo primero, se pueden citar los casos de un incendio que afectó a una vivienda de Blowing, donde no solo los vecinos prestaron ayuda el día del evento sino que varios meses después lo hicieron en la reconstrucción o, el incendio de que afectó a Valparaíso a comienzo del año 2017 y que se extendió hasta dos poblaciones vecinas a la Comunidad Piuke Ko, en este caso, la comunidad efectuó convocatorias públicas a través de medios digitales para ir en ayuda de sus vecinos, entre los cuales se contaban ex habitantes de la misma comunidad. Estas tareas, implicaron la contención del incendio, limpieza de las casas afectadas y reconstrucción de viviendas; según relataron los habitantes de Piuke ko, llegaron decenas de voluntarios a apoyar estas labores.

Con respecto a casos donde las redes han operado como plataforma para eventos contenciosos, se pueden citar como ejemplos, los conversatorios efectuados en la Ecoaldea El Vuelo del Sauce en oposición a la construcción del proyecto hidroeléctrico Alto Maipo; un encuentro nacional de la Red de Semillas Libres celebrado en la comunidad Buen Mundo que tuvo entre sus temas, acciones y resoluciones, oponerse a Ley de Obtentores Vegetales y al Convenio UPOV 91; el rechazo de los habitantes de la comunidad de Quitaqui al Parque Eólico Pelilin y a su línea de transmisión; las acciones de los integrantes de Minga Alegre en contra de la central hidroeléctrica HidroAysén y su posterior difusión a través de videos documentales o la movilización de Piuke Ko, Pueblo Libre y Barrios Bajinos contra el drenaje del humedal el Criquet por parte del Ejército de Chile.

\section{Significando la naturaleza}

Si bien, a la base de cada una de las prácticas mencionadas se encuentran una pluralidad de significaciones, la naturaleza ocupa un lugar central. Como tal, estará presente en la totalidad de ellas, a su vez, le serán asignados distintos sentidos por parte de los entrevistados. Entre ellos están:

El origen natural u orgánico de los objetos o alimentos. En esta acepción, lo natural u orgánico de las semillas o alimentos, materiales de construcción, medicinas u otros objetos, va a fungir como un criterio de calidad, que redundaría en beneficios para las personas y el medio ambiente.

[¿Cómo se busca que sean los alimentos?] Generalmente tratamos de que el alimento sea natural, como las papas y las quínoas que vamos a comprar y la vegetación que está afuera (Iván-1:04:26)

[¿Qué es la bioconstrucción?] La bioconstrucción es en el fondo, construir con materiales naturales, aprovechar lo que te da el lugar principalmente. (Mariel-2-1:13:30)

Lo no industrial. La naturaleza va a estar presente en lab opción por minimizar el uso de materiales y formas convencionales de construcción; en el no uso de agroquímicos, ni de semillas industriales; y, en la preferencia por medicinas alternativas y hierbas, antes que por la medicina alópata y los fármacos industriales. De este modo, lo industrial aparece como una de las cuestiones centrales a rechazar y por las cuales se opta por lo natural. En algunas ocasiones, lo industrial aparece significado como tumor que hay que extirpar o, como una cadena errada de utilización de recursos con efectos perniciosos tanto para 
la sociedad como para el medio ambiente; en otras en tanto, será considerado un mal necesario, que debe ser regulado en pos del bien común.

O sea, la industria, parte, nace en la naturaleza, la industria no existe sin la naturaleza, pero está destruyendo la naturaleza, es como un tumor. La naturaleza es un cuerpo, el tumor es parte de la naturaleza, es parte del cuerpo, pero eso no quita que esté matando al cuerpo, $[\ldots]$ La industria es un tumor de un cuerpo, y eso no quita que sea basura y haya que expulsarlo. (Horacio-2-30:00)

Recursos naturales. La naturaleza será entendida como una forma de obtención de recursos o financiamiento, ya sea por medio del compostaje, la recolección y el trueque; $\mathrm{o}$, a través de la venta de terapias, hierbas, ungüentos, cosméticos, semillas, cursos, talleres y proyectos. De tal forma, que el conocimiento de la naturaleza, permite la configuración de oficios y la producción de bienes bajo formas artesanales. Concomitantemente, la naturaleza es entendida como proveedora de recursos que permiten la subsistencia.

y ahí vamos jugando, vamos jugando a que el $[. .$.$] hace sus analgésicos naturales,$ que el $[\ldots]$ da sus talleres de medicina natural, que yo ando con mis semillas, que la $[\ldots]$ anda con su cosmética natural, que la $[\ldots]$ cocina, tiene plantas, hierbitas secas, entonces desde la misma naturaleza generamos nuestro sustento. (Roberto-1:27:00)

Activismo. El activismo relacionado con la naturaleza, va a englobar una serie de remisiones, tales como, protección, restauración, preservación o resistencia, que se traducen en el manejo que se le da a las plantaciones forestales, la recuperación de ecosistemas y bosque nativo; en la reutilización de desechos por medio del reciclaje y compostaje; en los contenidos abordados en los cursos, talleres y proyectos, en las temáticas de interés en la generación de redes, voluntariado y recepción de extranjeros; $\mathrm{y}$, en la valoración que se hace de la forma de vida de los pueblos originarios en el indigenismo. Estas acciones tienen en común la defensa de los aspectos naturales o nativos de los territorios en que se encuentran insertos los ApS. Dicho activismo, se disocia de la adscripción a corrientes político ideológicas tradicionales, poniendo como centro el vínculo e interés por la naturaleza en sí misma. Esta adscripción a la naturaleza va ser tematizada como una consciencia particular que se está extendiendo en la sociedad.

[¿̇en que consiste eso que tú le llamas un punto verde?] ¿en qué consiste? [no, más bien, lo que busca es un espacio de rescate] sí, de restauración ecológica, de que ahí surja, de que vuelva a restaurarse la vida. Así ya en el peor de los casos, es que el desierto llegue a Temuco ponte tú, $[\ldots]$ entonces este va a ser [un] oasis poh, como van a haber muchos otros, [...], la idea de trabajar en red con otros grupos es apoyarnos en eso cachai, yo creo que eso se comparte con varios, en este lugar van a haber semillas, están los árboles nativos que después van a empezar a tirarse para otras partes, vamos a poner agua, vamos a tener cosas para seguir viviendo más tranquilos. (Carolina-1-17:35)yo creo que hay que agarrar, agarrar la pala y el chuzo y defender los espacios naturales cachai. [...] entonces el activismo legal es mover montañas así con las manos, en un esfuerzo desmesurado para regularizar este espacio simplemente para que no pueda tomarlo cualquier industria $\mathrm{y}$ destruirlo, cachai. Eso ya para nosotros ha sido un esfuerzo sobremanera porque nadie [...] nos ha prestado ni un pelo de apoyo. (Horacio-2-15:00)

[Y si a esos grupos afines les asociáramos [...], algún nombre que tenga que ver con alguna ideología] podríamos decir que la etiqueta sería como a personas que buscan vivir en armonía con la naturaleza. (Iván-33:00) 
Ámbito de encuentro. La naturaleza aparece significada como un lugar de encuentro. La búsqueda por estar y vivir en ella constituye la motivación principal para trasladarse y conformar un ApS. En asentamientos con mayor número de habitantes, la atracción por lo natural -medicina, forma de vida, alimentos, construcciones- permite identificar redes internas.

[Y si tuvieras que [decir] algo que conectara a la gente...] La naturaleza [Ahá] Como que esa es la conexión yo creo. [...] a todos les gusta la naturaleza. (Gonzalo-3-12:15)

Yo siento que mucha gente que ya está colapsada en la ciudad, [...] y se da cuenta que sí o sí tiene que volver a la naturaleza, tener un contacto nuevamente con la naturaleza. [...] y ahí se van armando los grupitos, o se van armando ecoaldeas, como, de cierta forma comunidades. (Marcela-1-32:41)

Vida. A la naturaleza se le relaciona con la generación de vida y a los ciclos de muerte y nacimiento.

La naturaleza, es todo lo que está vivo, todo lo que nos rodea, nosotros mismo somos naturaleza. Para mí la naturaleza es la vida misma, es todo. [...], el flujo energético entre todas las cosas, también es un tiempo, espacio, eehh, no es solo lo material, también lo inmaterial, lo que no se ve. (Mariel-2-1:01:09)

Forma de Vida. El habitar un ApS, se asocia a una forma de vida que implica una vuelta a la tierra y que se vive en consonancia con su estudio y sus ciclos naturales. Este regreso a la naturaleza se experimenta como trabajo duro y como una oposición o alejamiento de la vida de las urbes y del consumismo neoliberal. Remite también, a privilegiar un espacio seguro, tranquilo y contenido, para el cuidado de hijas e hijos.

¿y qué se busca con esta forma de vida?] $[\ldots]$ lo que se busca en esta forma de vida es volver a la tierra, y volver a la tierra sin intervenirla de forma negativa, y no intervenirla sino como sumarte a sus ciclos naturales, como sentir a la tierra en todas sus expresiones, en trabajarla, comprenderla, [...]. (Roberto-32:24)

Mira, el contacto con la naturaleza es súper importante pero también el salir un poco del sistema viciado que existe en la ciudad y en general en el sistema capitalista, neoliberal, consumista, injusto, ya, [...], yo creo que también es algo revolucionario, no es solo querer estar en la naturaleza, sino que es haber vivido en un sistema y decís, esto ya no da para más, yo no creo en esto, [...] y es como seguir en un camino alternativo. (Mariel-2-28:10)

igual es duro vivir en el campo, si no es una vida de holgazán, el holgazán aquí no da fruto, así que aquí estamos poniéndole el hombro, [...] llegar a un lugar, armar su casa, abaratar, ser más prudente $[\ldots]$ con los gastos, no excederse. (Antonio-1-18:00)

Espiritualidad. La naturaleza se percibe como una totalidad o deidad, con la cual se establece un vínculo espiritual y ceremonial. Madre, Pachamama, Dios o todo, son algunas de las significaciones relacionadas que recibe.

[¿Qué es para ti la naturaleza?] Qué linda pregunta $[\ldots]$. El todo, Dios, todo, maestra, madre, cobija, enseña, protege, te remece también y maestra, eso. $\mathrm{Si}$, para mi es Dios. [O sea tienes un vínculo espiritual con la naturaleza] absolutamente. (Carolina-3-12:00)

[Para ti, ¿qué representa la naturaleza?] ¿La naturaleza? Todo lo que está en el planeta, que pertenece, la montaña, el río, las nubes, el viento, el fuego, todo. Todo lo que tenemos es naturalmente: sus seres, sus bichos, sus peces, sus 
animales, las aves, todo... [¿Y tienes alguna vinculación de tipo espiritual con la naturaleza?] Todo el rato. (Coloro-1-1:03:33)

[¿Qué es para ti la idea de naturaleza?] Oh, para mí, La naturaleza es como mi madre, yo no creo mucho en religiones, así como en Dios, pero para mí la naturaleza, es la madre. La pacha, eso para mí es la fuerza que existe y la que me da como fuerza, porque siento que ella nos da todo, siento que es lo más importante. [...]. Ese es como mi Dios, la naturaleza, porque ella es la que me da todo lo que necesito, tengo que aprovecharlo y cuidarlo, tengo un respeto enorme por ella. (Tatiana-2-30:08)

Armonía. La naturaleza alude a la armonía en tres sentidos, en tanto se produce una adaptación a sus ciclos temporales; a la sensación de equilibrio interno que logran las personas que viven en consonancia con ellos; y, a la cooptación por parte del mercado inmobiliario de aquellas sensaciones de bienestar que provoca el contacto con la naturaleza.

[si] concuerda con los ciclos naturales, [...] va a ser una persona que está equilibrada, que está en sintonía con la naturaleza, y al estar en sintonía con la naturaleza, va a tener un equilibrio en su mente también, y al tener un equilibrio en su mente va a poder juzgar, qué es lo que corresponde y qué es lo que no [...]. (Horacio-1-25:00)

¿cómo definimos naturaleza? Como la expresión de la vida. Como esa armonía, que te cambia ese ritmo, que cuando sale el sol te estay recién levantando y cuando [entra] el sol te estai acostando. Y en invierno el ritmo es distinto al ritmo del verano. (Felipe-3-16:00)

[...] creen estar en contacto con la armonía que te brinda la naturaleza, yo creo que es un motor, y si te fijai, como parte del mercado inmobiliario tiene que ver con eso, algo... cachai. [Claro, hay un vínculo en que mercado y naturaleza también] Sí po. Tienen plusvalía las casas con árboles, o si hay... hay edificios que se venden porque hay un parque o un pulmón verde que ni siquiera pertenece al edificio, lo promocionan igual si es que está cerca. (Gonzalo-4-01:45)

Norma. En tanto norma, se entiende que la naturaleza provee de un orden y formas de organización que, al ir en contra de ellas, esta se desvirtuaría.

Lo que pasa es que el hombre tiene conductas que son antinaturales, porque tiene una mentalidad extractivista, de acumulación, entonces eso es lo que genera que el hombre desvirtúe el sentido de la naturaleza, altere el orden natural. (Gonzalo-2-31:00)

[¿Acá existen acuerdos o normas básicas?] Mm... yo creo que la norma básica de aquí, que no está escrita en ningún lado, y ahora mismo te la voy a improvisar, pero es algo que si le preguntai a todos los que viven acá te van a decir que sí, yo creo que la naturaleza nos rige. (Horacio-1-28:03)

\section{Discusión}

A partir de los resultados anteriormente expuestos y en consonancia con la pregunta que guía este artículo, interesa abordar discusiones relativas a tres temas: el método; las formas que toma la acción colectiva contemporánea en un contexto de interés por el medio ambiente; $y$, dado que la naturaleza aparece como un significante articulador de las distintas prácticas, se discutirá también sobre la pluralidad de sentidos que le son asignados por parte de los entrevistados.

En relación a los aspectos metodológicos, una primera cuestión a discutir, refiere al número y dimensión de los casos 
seleccionados. Se estima que hubiese sido un error intentar alguna forma de extrapolación a partir de un único asentamiento, debido a que la diversidad de recursos económicos, zonas bioclimáticas y antigüedades, entre otras diferencias, pueden llevar a considerar que lo que ocurre en un lugar es idéntico o similar a lo que ocurre en otros asentamientos. Error que fácilmente puede traducirse en la generalización de los resultados de un caso único a un fenómeno complejo. De hecho, durante el comienzo de la fase exploratoria, se visitó un par de asentamientos en que lo ceremonial, cantos devocionales y ofrendas a lo sagrado estaban presentes por doquier. De forma tal, que se asumió que estas prácticas describían buena parte del fenómeno. Sin embargo, con el paso del tiempo y asentamientos visitados se constató, que se trataba más bien de una de las corrientes que influyen y están presentes en él, la cual admite diferentes adscripciones o simpatías dependiendo de las particularidades del ApS. En algunos casos, se trataba a esta corriente, no solo con distancia, sino que también, con abierta ironía. No obstante, y debido a que tanto la literatura internacional como nuestro propio catastro describen la presencia de asentamientos con orientación hacia las prácticas espirituales o religiosas, se considera que una inmersión de unos 30 días en uno de ellos, permitiría una mayor comprensión del fenómeno en nuestro país. Una segunda cuestión emergente de carácter metodológico, dice relación con la forma en que se lleva a cabo la etnografía. En este caso, fue fundamental dormir en los lugares, escuchar los sonidos de los diferentes horarios, incorporar el lenguaje, las canciones y bromas cotidianas. Oscilar entre un observador participante y participante observador (Kawulich, 2005). En este sentido, es discutible que visitas esporádicas y diurnas, logren traspasar los umbrales del sentido común. En mi experiencia investigativa, tomaba por lo general 10 días continuos avanzar más allá de la deseabilidad social y comenzar a inferir las tensiones subyacentes a las apariencias.
Con respecto a la acción colectiva contemporánea la primera cuestión a discutir concierne a la perspectiva desde la cual se observa e interpreta el objeto de estudio. $\mathrm{Y}$ si bien, en este caso se ha optado por hacerlo, como ya se dijo, desde la teoría de los movimientos sociales, en modo alguno es posible sostener que el fenómeno de los ApS se reduce a un movimiento social. En efecto, objetos similares o que se traslapan con este, han sido leídos desde distintos ángulos, entre otros, migraciones (Hidalgo \& Zunino, 2012; Nogué, 1988; Zunino \& Hidalgo, 2010) comunidades (Lombardozzi, 2017), huella energética (Blaitt, 2010) o agroecología (De Matheus \& Silva, 2013). Desde nuestra perspectiva, lo relevante en la selección teórica, es que el objeto no quede clausurado por ella, de modo tal, que no se confunda o reduzca el fenómeno a una de sus dimensiones o entradas, y que, la teoría a ocupar, brinde material interpretativo que permita comprender aspectos del mundo contemporáneo o de procesos histórico sociales.

Ahora bien, la noción misma de movimiento social admite diferentes concepciones. Autores como Tilly \& Wood, (2010) o Iglesias (2005), afirman que es un hecho empírico que se caracteriza por un reportorio de movilizaciones públicas de carácter contencioso. Como ya se ha visto, se ha preferido tomar distancia de aquella noción, asumiendo que un movimiento social corresponde a una constelación de elementos que abarca, en forma bidireccional, desde la vida cotidiana hasta las manifestaciones públicas; integrando durante su existencia a grupos, individuos, repertorios de acción colectiva, demandas y disputas en diferentes niveles. Siguiendo a Melucci (1994a, 1999), la trayectoria de estos actores colectivos, oscila entre los momentos de latencia y de visibilidad. El momento visible, la protesta o manifestación pública, constituirá un importante repertorio de acción colectiva, sin embargo, en caso alguno el movimiento puede reducirse a ella. 
Del mismo modo, es posible considerar que los movimientos sociales contemporáneos no se acotan en el ámbito conflictual, sino que también implican aspectos generativos, tales como, la construcción de espacios de experiencia que les permiten a los protagonistas vivir de acuerdo a sus principios y aspiraciones (Pleyers, 2010). Dado que la concepción que clausura a los movimientos sociales en su etapa visible y de conflictividad pública ha sido una de las más influyentes, se le ha dado escasa importancia al espacio que se produce al interior de sí mismos. Por el contrario, indagar en las tensiones, contradicciones y potencialidades que se presentan en la cotidianidad de los movimientos y en sus espacios de convivencia, puede abrir al conocimiento aspectos que muchas veces se soslayan. En este sentido, se ha criticado el rol emancipador que puedan cumplir las ecoaldeas -y, por extensión los ApS-, dentro de ellas, se retomarán las referidas al elitismo y al apoliticismo del filósofo político griego Takis Fotopoulos (2000, 2006).

El elitismo. Fotopoulos, plantea que los ApS están conformados por sujetos de clases medias o acomodadas y que su estilo de vida reproduce las asimetrías sociales. Para responder a esta crítica es necesario hacer una primera distinción. Grosso modo, y siguiendo el argumento de Dias, Loureiro, Chevitarese, \& Souza (2017) y Dawson (2013), los ApS de países desarrollados o del norte global se avienen a esta descripción, mientras que, los países en vías de desarrollo, no. Prueba de esto serían las redes de asentamientos de Sri Lanka, Senegal o India (Litfin, 2009).

Sin embargo, la distinción anterior no impide que dentro de un mismo continente o incluso país, las asimetrías se puedan mantener. En el caso de Chile, hay estudios como los de Lazo (2012) y Zunino \& Huiliñir-Curío (2017) en los que se afirma, que dos asentamientos relacionados al fenómeno de los ApS, corresponden a sectores socioeconómicos medios y altos; por otra parte, los datos empíricos recabados durante el trabajo de campo de esta investigación, parecen señalar, que uno de los asentamientos mantenía esta misma segmentación, otro integraba sectores medios medios y medios bajos; mientras que el tercer asentamiento, integraba sectores medios bajos y bajos. Es decir, en la actualidad, existirían una pluralidad de sectores socioeconómicos entre los distintos ApS. De tal modo, que algunos mantendrán la desigual estructura socioeconómica nacional, mientras que otros, tendrán un efecto cohesionador entre diferentes sectores.

Otra entrada al tema de la elitización de este fenómeno, dice relación con las fuentes que han influenciado sus modos de construcción. Al parecer, se dan de modo concomitante tres fuentes de influencia: la vida rural; la auto construcción por necesidades económicas; $\mathrm{y}$, los conocimientos provenientes de la arquitectura o del diseño, que en sus inicios y por lo general, requerían de formación en el extranjero. Probablemente por acceso a distintos tipos de recursos, fue esta última fuente la que alcanzó mayor notoriedad e influencia, mientras que las otras fuentes fueron y han sido invisibilizadas. Esto no obsta que se presente un tipo de elitización que tiene que ver con conocimientos especializados ligados a la bioconstrucción, ni que los poseedores de estos conocimientos, puedan ser contratados por una élite económica para la construcción de sus casas. En efecto, ambas cuestiones ocurren. Sin embargo, debido a la profusa información que existe hoy día en internet sobre el tema y, a la cantidad de talleres y cursos, gratuitos y pagados que se ofrecen; el conocimiento de estas técnicas se ha ido horizontalizando y expandiendo, produciendo un efecto de deselitización del fenómeno. Simultáneamente, el oficio de biocontructor, parece ser una actividad cada vez más requerida por sectores de ingresos medio y altos, connotando con 
ello la emergencia de una plusvalía de lo natural y su hibridación con el capitalismo verde o sostenible (O'Connor, 2000).

El apoliticismo. Fotopoulos (2000, 2006) plantea que la orientación de los ApS a la vida cotidiana y su consecuente abandono de la esfera macro, no produce, ni producirá, cambios estructurales en la sociedad, ni menos, en sus instituciones estatales. Está critica es compartida por Zunino \& Huiliñir-Curío (2017) y por Salamanca \& Silva (2015). Para profundizar en la dimensión política de los ApS, es necesario retomar la descripción general que se hizo sobre la acción colectiva al comienzo de esta investigación. Se señaló anteriormente, que la acción colectiva pasó desde la acción preferente hacia el Estado a orientarse hacia la vida cotidiana. De este modo, los partidos y sindicatos, entre otras organizaciones de la matriz tradicional, se fueron vaciando de militantes, mientras que, en la etapa posterior, emergen una serie de luchas fundadas en identidades particulares, que canalizarán el activismo social hacia la creación de micro esferas de influencia.

Esta transformación, también se verá reflejada en las trayectorias de buena parte de los habitantes de los ApS. En efecto, la mayor parte de las personas entrevistadas, señalaron haber participado en manifestaciones públicas mientras estudiaban en la educación secundaria, superior o de forma previa a vivir en los asentamientos; sin embargo y de manera coincidente, argumentaban que en algún momento comenzaron a descreer de éste repertorio de acción colectiva debido a los escasos resultados obtenidos y si bien, no descartaban del todo movilizarse, consideraban que la forma de vida que llevaban en la actualidad era su principal protesta contra el sistema socioeconómico y sociopolítico imperante. En este sentido, criticaban a quienes acudían a movilizaciones masivas, pero que, simultáneamente, mantenían una vida que reproducía en todas sus formas el modelo socioeconómico al que decían oponerse. Por cierto, al considerar a su propia forma de vida como método de protesta hacían referencia a que los asentamientos en sí mismos y a través de sus prácticas, constituyen una demostración de que es posible vivir alejado de los patrones convencionales del consumo y de la degradación medioambiental; y a que, por medio de los cursos, talleres, visitas a colegios o la participación en ferias y exposiciones se sensibiliza y socializa a otros individuos en su imaginario colectivo. De este modo, la experiencia práctica en el territorio se entiende como un tipo de acción colectiva que guarda coherencia entre los anhelos y el comportamiento efectivo.

Señalado lo anterior, queda meridianamente claro que, como efecto de una tendencia global y nacional de despolitización de las instituciones del Estado nación, buena parte de los habitantes de los ApS han optado por desatender las transformaciones estructurales y abandonado la disputa por el Estado, con el consecuente riesgo que esto implica para los valores e intereses que ellos mismos propugnan. Riesgo, constatado por Harvey (2007), cuando señala que fue la demanda por la libertad de los movimientos de los años 60, la que pavimentó la cooptación del Estado por parte del neoliberalismo. Sin embargo, y dado el contexto de despolitización actual, la interrogante debe apuntar a si el fenómeno de los ApS contribuye o no a una repolitización de la sociedad.

A un cierto nivel, parece hacerlo. Existe evidencia que avala el hecho de que las redes favorecen la emergencia de identidades que disputan los códigos culturales que orientan a la sociedad (Melucci, 1994a, 1999); que logran poner temas y demandas en la agenda pública (McAdam, 1999); y que, constituyen una pre condición para que los activistas se integren a formas de participación que operan por fuera de los canales institucionales formales (Della Porta \& Diani, 2011; Diani, 2009). Si se entiende la politización de la sociedad, como el proceso por el cual un tema pasa a formar parte del debate público, Programa de las Naciones Unidas para el 
Desarrollo (PNUD) (2015), los ApS, a través de sus redes, contribuyen no solo a poner temas medioambientales en discusión, sino que también, a promover organización y estilos de vida en torno a ellos.

La conformación de redes por parte de los ApS es un hecho empírico no solo observado como práctica en esta investigación, sino que también, por otros estudios (Dias et al., 2017; Pereira \& Bernete, 2017). Estas, operan en escalas vecinales, locales, nacionales, continentales y mundiales; poseen boletines informativos, páginas web, editan libros y difunden cooperativamente sus actividades. Cada ApS, en sí mismo, parece constituir un nodo de esta red (Dias, et al., 2017), en el que se intersectan una serie de colectivos, activistas e individuos mediados por las temáticas ambientales. Una suerte de rizoma en el sentido de Deleuze \& Guattari (2004), a través del cual, los territorios son irrigados con significaciones que se oponen, superponen e hibridan con otras de carácter hegemónico. Por cierto, esta estrategia tiene sus límites. Como afirma Trainer (2002) en respuesta a los argumentos de Fotopoulos, los ApS no apuntan a la toma del poder, estrategia que comprende a la dimensión estructural como un compartimento estanco que debe ser asaltado, sino que, por el contrario, asumen su interrelación e influencia recíproca con la esfera cultural. Es decir, la acción colectiva de los habitantes de los ApS se orienta preferentemente hacia la vida cotidiana, sin embargo, no termina ahí, sino que se extiende hacia ámbitos de influencia más generales, cuestión que, parece acelerarse, en la medida que surgen más nodos y mayor interconexión entre ellos.

Ahora bien, el hecho de que un fenómeno colectivo contribuya a la politización de la sociedad, no implica necesariamente un contenido univoco, generativo o virtuoso como resultado de aquel proceso. Si el imaginario colectivo de los ApS va a poner en el centro de su acción la cuestión de la naturaleza, el resultado del proceso de politización al cual contribuye, estará dado por las disputas en torno su significado.

Los distintos sentidos asignados a la naturaleza por parte de los entrevistados, pueden ir desde una concepción instrumental, entendiéndola como un ámbito que provee de recursos para satisfacer las distintas necesidades humanas a, un sentido espiritual, en que se le deifica, connotándola como una totalidad armoniosa sobre la cual el ser humano irrumpe de modo irresponsable, atentando contra su equilibrio. Será está última acepción motivo de crítica, tanto para el ya citado Fotopoulos $(2000,2006)$, como para Žižek (2011).

Ambos, van a cuestionar que la irracionalidad de estas ideas puede abrir la puerta a neototalitarismos. En el caso del primero, plantea que el movimiento de ecoaldeas está "dominado por filosofías irracionales" (Fotopoulos, 2006, p.5), pone como ejemplo la adscripción a GEN de comunidades budistas o neopaganas, agregando que "un proyecto antisistémico requiere de una filosofía racional fundada en la democracia como una estructura y un proceso de autoinstitución social [...] en lugar de instituciones religiosas o de otro tipo" (Fotopoulos, 2006, p.4).

Frente a esta crítica, se coincide en la importancia de que un proyecto democrático se funde en las decisiones autónomas de la sociedad, y que, conjuntamente, se distancie de normas con origen extra social (Castoriadis, 2005). Ahora bien, la autonomía social contiene como prerrequisito la autonomía individual (Castoriadis, 2002), lo que incluye la libertad de culto. El hecho de que los habitantes de ciertos ApS o algunos de estos en su conjunto, sostengan creencias metafísicas o irracionales, no tendría por qué impedir, la deliberación racionalmente fundamentada de las normas que rigen al conjunto.

Por otra parte, ni la búsqueda espiritual ni la racional, son, necesariamente, garantías de eludir o caer en totalitarismos 
y si bien es cierto, que emergen creencias míticas poco fundamentadas en algunos asentamientos, también lo es, que estas cuestiones se debaten y que son objeto de cuestionamiento por parte de sus habitantes. Asumir que este tipo de creencias se extrapolarán linealmente para influir en la conformación de los mundos venideros, es tan errado, como creer en la multiplicación de estos asentamientos para el reemplazo del modelo socioeconómico actual. Será pues, la deseable reflexión crítica en una sociedad democrática, la que, junto con alejar los influjos totalitarios, permita el ejercicio espiritual sobre la base de un respeto irrestricto a los derechos fundamentales.

Otra arista de esta cuestión, queda bien expresada por Huiliñir-Curío \& Zunino (2017, p.156), cuando advierten que la reclusión o aislamiento en que puedan caer estos asentamientos degenere en "un mundo ilusorio, artificial, exclusivo y segregado". En efecto, la mezcla de ideas irracionales sumado a un alto aislamiento puede ser terreno fértil para la formación de sectas destructivas. Este riesgo aumenta, cuando se trata de comunidades cuyos objetivos son espirituales u operan bajo la dirección de liderazgos carismáticos. Por el contrario, en el caso de los ApS que se han indagado, la deliberación colectiva, la ausencia de liderazgos centralizados, el alto grado de interacción con el entorno y su interés explícito en vincularse hacia el medio social a través de la construcción de redes, reducen la posibilidad de dar cabida a sectas, aunque no las inocula de que personas con intereses sectarios realicen actividades o busquen adeptos en ellas, o que incluso, la naturaleza misma, se convierta en excusa ideológica para su conformación.

En relación a la crítica de Žižek (2011, p.63), va a plantear que frente a la amenaza ecológica se fantasea con la idea de una naturaleza armónica y en equilibrio, cuando en realidad se trata de una sucesión de catástrofes de magnitudes colosales; llegando a afirmar que, "Si la Tierra es nuestra madre, es una pálida madre sedienta de sangre". Es posible coincidir con él, respecto a que en determinada escala la naturaleza es una sucesión de catástrofes y que estas dejan desechos que no son necesariamente reciclados, las más de las veces quedan dispersos por el ambiente, otras, como en el caso del petróleo, únicamente contenidos. En un futuro y en aquella amplia escala temporal a la que hace referencia Žižek, la mayor parte de las formas de vida que se conocen, incluyendo a la humana, estarán probablemente extintas. El argumento de Žižek puede resultar peligroso si se excluyen de su reflexión escalas de menor tamaño temporal, que reportan el equilibrio necesario para la vida de numerosas especies. En una escala de decenas de miles de años, eventualmente, da lo mismo lo que la especie humana haga, ya que todo conduce indefectiblemente a una destrucción tras otras. Por el contario, la apelación a una naturaleza armónica $\mathrm{y}$ en equilibrio, junto a lo que tiene de idealización, atiende también a los rangos y ciclos ambientales que posibilitan la existencia de la vida y a la intervención del ser humano en ellos.

Adicionalmente, Castoriadis, (2006), Fotopoulos (2006) u O'Connor (2000) han advertido que si el ecologismo se centra en la naturaleza o en la ecología como un tema único, esencializado y apolítico, "podemos imaginarnos regímenes autoritarios que imponen restricciones draconianas a una población enloquecida y apática" (Castoriadis, 2006, p.265), ya que, las cuestiones relacionadas a la escasez y la sostenibilidad, siempre podrán ser resueltas por élites que no verán afectados sus privilegios, con medidas coercitivas sobre las clases trabajadoras y los más débiles de la sociedad (Fotopoulos 2006, p.2). Por el contrario, si el ecologismo se hace parte de un proyecto antisistema mayor, integrándose a otros movimientos emancipatorios, eventualmente diluirá parte de su identidad, aunque simultáneamente, reducirá el riesgo de caer en autoritarismos 
y de su cooptación por parte de políticas neoliberales (Castoriadis, 2006; Fotopoulos, 2006; O'Connor, 2000). Desde ahí, que sea necesario "desnaturalizar la naturaleza" (Bustos, Prieto \& Barton, 2015, p.22), la ecología y la sustentabilidad. Es decir, asumir su carácter contingente, conflictivo y político, en aquella escala que hace posible la vida humana.

\section{Conclusiones}

Los procesos de territorialización que se llevan a cabo a través de las distintas formas de ApS en Chile, han ido en aumento, si se toma por referencia el número de casos durante los últimos años. Estos procesos, materializan un imaginario colectivo a través de un conjunto de prácticas recurrentes que se llevan a cabo con distinta intensidad en cada lugar y que tienen como uno de sus sentidos convergentes a la naturaleza.

El despliegue de este imaginario colectivo produce una forma de vida que es considerada por parte de los habitantes de los asentamientos como portadora de valores $\mathrm{e}$ intereses diferentes $u$ opuestos a los que animan la vida urbana convencional. De este modo, el habitar en un entorno cercano o inserto en la naturaleza, alejado de la congestión, polución y hacinamiento de las grandes ciudades, y que, simultáneamente, es crítico de las formas de producción industrial, ha ido ganando adeptos. Quizás por ello, estos espacios están expuestos y reciben presiones por parte del mercado inmobiliario relacionado, que aumentan la plusvalía de los territorios y sus construcciones, he imitan la estética de sus prácticas de un modo desanclado de su potencia contra productivista. No obstante, es posible afirmar que dichas presiones no han mermado la creación de nuevos ApS y la replicabilidad de sus prácticas en contextos de escaso poder adquisitivo. En efecto, el caso del asentamiento Piuke Ko, evidencia que existen tomas de terrenos o familias al interior de ellas que optan por esta forma de vida y sus técnicas de edificación.

$\mathrm{Si}$ los procesos de territorialización implican la materialización de un imaginario, podemos afirmar a través de este caso, que el imaginario colectivo que busca materializar formas de vida sustentables se encuentra en expansión y que, al menos por el momento, está lejos de su colonización total por parte del capitalismo. Desde luego, con esto, no se plantea que los ApS por definición sean anticapitalistas, sino que, tanto en sus prácticas como en sus significaciones, se opera en variados aspectos con lógicas diferentes a las que promueven o reproducen la acumulación incesante del capital.

Un rol fundamental en la preservación de los modos de convivencia no capitalistas, lo constituye la existencia de un conjunto de prestaciones y contraprestaciones recíprocas que ocurren sin la mediación del dinero, tales como la minga o el trueque, a través de la cuales se promueve no solo el intercambio, sino que también, el fortalecimiento de la pertenencia comunitaria. Y si bien, no es posible afirmar que por medio de este conjunto de contraprestaciones recíprocas los asentados obtengan la mayor parte de su sustento, sí es constatable, que forma parte de sus dinámicas diarias, al punto de que la mayoría de las construcciones han sido, en buena parte, edificadas bajo formas de intercambio no monetarias.

En relación a la interrogante sobre qué formas adquiere la acción colectiva contemporánea en un contexto de motivaciones medioambientales. $\mathrm{Se}$ observa, a partir del fenómeno de los ApS, que se centra en la vida cotidiana en mayor medida que en la acción contenciosa y pública. Sin embargo, no se queda solo allí, ya que lo político, en tanto disputa de intereses y cuestionamiento de las relaciones 
de poder, se tematiza constantemente y se vuelca, por medio de talleres, encuentros, y redes, a la socialización de otros individuos y hacia la replicabilidad de sus prácticas. De tal modo, que cada asentamiento, se constituye en un nodo de acción colectiva. En una suerte de reemplazo de la labor formativa que, en la matriz política centrada en el Estado nacional, era realizada por los partidos políticos.

Lo anterior, permite plantear que los ApS, constituyen un espacio de transición sociocultural que oscila entre una forma de vida y un movimiento social orientado al conflicto público. Este espacio intersticial, es posible entenderlo desde la perspectiva de la acción colectiva, como un movimiento sociocultural, ya que si bien, en todo movimiento social existe una dimensión cultural, es solo una parte de ellos, la que pone el énfasis de su acción en los espacios de convivencia cotidiana. Disputando a ese nivel los valores que orientan a la sociedad.

Ahora bien, el abandono o la atención marginal que prestan los habitantes de los ApS hacia la política formal no es innocuo, por el contrario, trae como consecuencia la influencia residual en el Estado del imaginario promovido por los asentamientos, quedando este a merced de su cooptación por parte de quienes sostienen imaginarios antagónicos.

Asimismo, el fenómeno de los ApS no se centra en una identidad o temática particular, como en los casos de los movimientos indígenas, feminista o ecologista; sino que se presenta como un entramado cultural en el que se intersectan, de modo fluido, distintas identidades. En este punto, cabe preguntarse, ¿qué significante es capaz de articular estas identidades, prácticas y redes? Ese significante, parece no ser otro que la naturaleza que, en sus diferentes sentidos, tensiones y contradicciones, se proyecta como un meta relato que aglutina a una parte no menor de la acción colectiva contemporánea.

\section{Agradecimientos}

Agradezco a CONICYT la beca CONICYTPCHA/Doctorado Nacional/2015-21150831 que permitió desarrollar parte importante de esta investigación.

\section{Referencias}

Albertín, P. \& Íñiguez, P. (2010). Un estudio etnográfico de usuarios de heroína: el uso de práctica reflexiva. EMPIRIA. Revista de metodología de ciencias sociales, 20, 39-60. https://doi.org/10.5944/ empiria.20.2010.2039

Ameigeiras, A. (2006). El abordaje etnográfico en la investigación social. En I. Vasilachis (Coord.), Estrategias de investigación cualitativa (pp. 107-151). Barcelona: Gedisa.

Arribas, S. (2008). Cornelius Castoriadis y el imaginario político. Foro interno, 8, 105-132. Recuperado de https://revistas. ucm.es/index.php/FOIN/article/viewFile/ FOIN0808110105A/7870

Auyero, J. (2000). Cultura política, destitución social y clientelismo político en Buenos Aires. Un estudio etnográfico. En M. Svampa (Ed.), Desde abajo. La transformación de las identidades sociales ( $3^{\mathrm{a}}$ ed.; pp. 181-208). Buenos Aires: Biblos.

Bengoa, J. (2007). La emergencia indígena en América Latina ( $2^{\mathrm{a}}$ ed.). Chile: Fondo de cultura económica. ISBN: 978-956-289-0540 . Recuperado de https:/trabajosocialucen. files.wordpress.com/2012/04/la-emergenciaindigena-en-america-latina_-jose-bengoa.pdf

Blaitt, R. (2010). La estructura social de comunidad y su aporte en la búsqueda de sostenibilidad: el caso de las ecoaldeas. Cuaderno de investigación urbanística, 69, 14-32. Recuperado de http://polired.upm.es/ index.php/ciur/article/view/337 
Berger, P. L. \& Luckmann, T. (1967). La construcción social de la realidad. Buenos Aires: Amorrortu. ISBN: 9789505180097

Bustos, B. G., Prieto, M., \& Barton, J. R. (2015). Ecología política en Chile: naturaleza, propiedad, conocimiento $y$ poder. Santiago de Chile: Editorial universitaria. ISBN13: 9789561124653

Calhoun, G. (2002). Los nuevos movimientos sociales de comienzos del siglo XIX. En M. Traugott (Comp.), Protesta social, repertorios y ciclos de acción colectiva (pp. 193-241). Barcelona: Editorial hacer.

Cancino, L. (2011). Aportes de la noción de imaginario social para el estudio de los movimientos sociales. Polis (Santiago), 10(28), 69-83. https://doi.org/10.4067/ s0718-65682011000100005

Cancino, L. (2015). Movimientos sociales y el proyecto de autonomía. Reflexiones desde el pensamiento de Castoriadis. Prometeica, revista de filosofia y ciencias, 11, 6-17. Recuperado de https://dialnet.unirioja.es/ servlet/articulo? codigo $=5156246$

Canteros, E. (2011). Las agrupaciones vecinales en defensa de los barrios. La construcción política desde lo local. Polis (Santiago), 10(28), 85-99. Recuperado de http://dx.doi.org/10.4067/S071865682011000100006

Castells, M. (1999). La era de la información: economía, sociedad y cultura. El poder de la identidad. (Vol. II): (5 Reimpresión). México: Siglo veintiuno editores. ISBN: 968-23-2169-7

Castells, M. (2012). Redes de indignación y esperanza: los movimientos sociales en la era de internet. Madrid: Alianza editorial. ISBN: 9788420609607
Castoriadis, C. (1998). Hecho y por hacer. Pensar la imaginación. Buenos Aires: Edudeba. ISBN: 9788494686870

Castoriadis, C. (2002). Figuras de lo pensable ( $2^{\mathrm{a}}$ Ed.). México: Fondo de cultura económica. ISBN: 9681664574 , 9789681664572

Castoriadis, C. (2005). Los dominios del hombre. Barcelona: Gedisa. ISBN: 97884-7432-299-6

Castoriadis, C. (2006). Una sociedad a la deriva: entrevistas y debates (1974-1997). Buenos Aires: Katz. ISBN: 8460983617 , 9788460983613

Castoriadis, C. (2007). La institución imaginaria de la sociedad. Buenos Aires: Tusquets editores. ISBN: 9871210566, 9789871210565

Cefaï, D. (2009). Como nos mobilizamos? A contribuição de uma abordagem pragmatista para a sociologia da ação coletiva. Dilemas: Revista de estudos de conflito e controle social, 2(4), 11-48. Recuperado de https://revistas.ufrj.br/ index.php/dilemas/article/view/7163

Cefaï, D. (2011). Diez propuestas para el estudio de las movilizaciones colectivas. De la experiencia al compromiso. Revista de sociología, 26, 137-166. https://doi. org/10.5354/0716-632x.2011.27491

Chihu, A. (1999). Estrategias simbólicas y marcos para la acción colectiva. Anuario de sociología, Polis 99, 41-65. https:// revistas-colaboracion.juridicas.unam.mx/ index.php/polis/article/view/16723/14959

Christian, D. (2003). Creating a life together: Practical tools to grow ecovillages and intentional communities. Canada: New society publishers. ISBN: 
0-86571-471-1. Recuperado de http:// library.uniteddiversity.coop/Ecovillages and_Low_Impact_Development/ Creating_a_Life_Together-Practical Tools_to_Grow_Ecovillages_and Intentional_Communities.pdf

Concha, C. (2010). La Ecoaldea El Romero. Etnografía a una comunidad alternativa de nuestro país. (Memoria de título inédita). Universidad de Chile. Santiago de Chile.

Dawson, J. (2013). From islands to networks: the history and future of the ecovillage movement. En J. Lockyer \& J. Veteto, Environmental anthropology engaging ecotopia: bioregionalism, permaculture, and ecovillages (pp. 217234). New York-Oxford: Berghahn books.

Debord, G. (1995). La sociedad del espectáculo. Santiago de Chile: Ediciones naufragio. ISBN: 978-84-8191-4429. Recuperado de http://criticasocial.cl/ pdflibro/sociedadespec.pdf

Della Porta, D. \& Diani, M. (2011). Los movimientos sociales. Madrid: Editorial complutense. ISBN: 978-84-9932-106-0

De Certeau, M. (1990). La invención de lo cotidiano. 1 Artes de hacer. México D.F.: Universidad Iberoamericana - Instituto tecnológico y de estudios superiores de occidente. ISBN: 2-07-032576. Recuperado de https://circulosemiotico. files.wordpress.com/2012/10/de-certeaumichel-la-invencion-de-lo-cotidiano-1artes-de-hacer.pdf

Deleuze, G. \& Guattari, F. (2004). Introducción: Rizoma. En Autor, Mil mesetas. Capitalismo y esquizofrenia

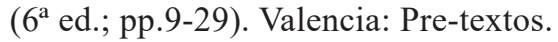

De Matheus \& Silva, L. (2013). Sembrando nuevos agricultores: contraculturas espaciales y recampesinización. Polis (Santiago), 12(34), 57-71. https://doi. org/10.4067/s0718-65682013000100004

Diani, M. (2009). The structural bases of protestevents.Actasociológica, 52(1),63-83. https://doi.org/10.1177/0001699308100634

Dias, M., Loureiro, C., Chevitarese, L., \& Souza, C. (2017). Os sentidos e a relevancia das ecovilas na construção de alternativas societárias sustentáveis. Ambiente \& sociedade, 20(3), 81-98. http://dx.doi. org/10.1590/1809-4422asoc0083v2032017

Ergas, C. (2010). A model of sustainable living: collective identity in an urban ecovillage. Organization \& environment, 23(1), 32-54. https://doi. org/10.1177/1086026609360324

Estenssoro, F. (2009) Medio ambiente e ideología: la discusión pública en Chile, 1992-2002: antecedentes para una historia de las ideas políticas a inicios del siglo XXI. Santiago de Chile: Universidad de Santiago. ISBN: 9563030605,9789563030600

Escobar, A. (2000). El lugar de la naturaleza y la naturaleza del lugar: ¿globalización o postdesarrollo? En E. Lander (Comp.), La colonialidad del saber: eurocentrismo $y$ ciencias sociales. Perspectivas Latinoamericanas (pp. 113-143). Buenos Aires: CLACSO, Consejo Latinoamericano de Ciencias Sociales.

Federovisky, S. (2011). Historia del medio ambiente: la transformación de la naturaleza de mundo ajeno y amenazante a espacio por conquistar. La génesis del movimiento ambientalista. Buenos Aires: Capital intelectual. ISBN: 9789876140287

Fernandes, B.M. (2005). Movimentos socioterritoriais e movimentos socioespaciais: contribuição teórica para uma leitura geográfica dos movimentos 
sociais. Revista nera, (6), 24-34. Recuperado de http://revista.fct.unesp.br/ index.php/nera/article/view/1460/1436

Fernandes, B. M. (2008). La ocupación como una forma de acceso a la tierra en Brasil: una contribución teórica y metodológica. En S. Moyo \& P. Yeros (Coord.), Recuperando la tierra. El resurgimiento de movimientos rurales en África, Asia y América Latina (pp. 978-987). Buenos Aires: CLACSO, Consejo Latinoamericano de Ciencias Sociales.

Flacks, R. (1994). The party is over ¿Qué hacer ante la crisis de los partidos políticos? En E. Laraña \& J. Gusfield (Eds.), Los nuevos movimientos sociales: de la ideología a la identidad (pp. 443466). Madrid: CIS. ISBN: 8474762030 , 9788474762037

Fotopoulos, T. (2000). The limitations of life-style strategies: The ecovillage 'movement'is NOT the way towards a new democratic society. Democracy \& Nature: International Journal of Inclusive Democracy, 6(2). Recuperado de https:// www.democracynature.org/vol6/takis_ trainer_reply.htm

Fotopoulos, T. (2006). Is the eco-village movement a solution or part of the problem? The international journal of inclusive democracy, 2(3), 1-5. Recuperado de https://www.inclusivedemocracy.org/ journal/vol2/vol2_no3_Takis_eco_village. $\mathrm{htm}$

Foucault, M. (1993). Microfísica del poder. España: Ediciones la piqueta. ISBN: 9788474430172

Garcés, M. (2002). Tomando su sitio. El movimiento de pobladores en Santiago, 1957-1970. Santiago de Chile: Lom ediciones. ISBN: 9562824772 , 9789562824774
Gamson, A. \& Meyer, D. (1999). Marcos interpretativos de la oportunidad política. En D. McAdam, J. McCarthy, \& M. Zald (Eds.), Movimientos sociales, perspectivas comparadas (pp. 389-412). Madrid: Istmo.

García, A. (2012). Indigenous autonomies and the multinational state. En A. L. Bialakowsky, P. Gentili, P. H. Martins, S. Lago, M. Langieri, C. Mera, ... B. Wehle (Comp.), Latin American critical thought: theory and practice (pp. 27-82). Buenos Aires: CLACSO.

Garretón, M. A. (2001). Cambios sociales, actores y acción colectiva en América Latina. Santiago de Chile: CEPAL, Serie políticas sociales. ISBN: 92-1-3219121. ISSN: 1564-4162 Recuperado de https://repositorio.cepal.org/bitstream/ handle/11362/6012/S 0110833 . es.pdf?sequence $=1 \&$ isAllowed $=\mathrm{y}$

Geertz, C. (2006). La interpretación de las de las culturas (11 ${ }^{\mathrm{a}}$ Reimpresión). Barcelona: Gedisa. ISBN: 8474323339, 9788474323337 (1996)

Giannini, H. (1999). La 'reflexión'cotidiana. Hacia una arqueología de la experiencia. Santiago de Chile: Editorial Universitaria. ISBN: 956-11-1720-7

Guber, R. (2011). La etnografía. Método, campo y reflexividad. Buenos Aires: Siglo veintiuno editores. ISBN 978-987-629157-6

Harvey, D. (2007). Breve historia del neoliberalismo. Madrid: Ediciones akal. ISBN 978-84-460-2517-7

Harvey, D. \& Fernández, S. (2011). La recuperación de la ciudad en la lucha anti-capitalista. Revista geográfica del sur, 2(1), 11-23. Recuperado de http:// www.revgeosur.udec.cl/wp-content/ uploads/2016/08/revgeosur_N1_harvey.pdf 
Hidalgo, R. \& Zunino, H. (2012). Negocio inmobiliario y migración por estilos de vida en la Araucanía lacustre: La transformación del espacio habitado en Villarrica y Pucón. Revista AUS, 11, 10-13. https://doi. org/10.4206/aus.2012.n11-03

Hobsbawm, E. (2007a). La era del imperio, 1875-1914. Buenos Aires: Crítica. ISBN: 978-84-9892-595-1

Hobsbawm, E. (2007b). La era del capital, 1848-1875. Buenos Aires: Crítica. ISBN: 848432-529-6

Huiliñir-Curío, V. \& Zunino, H. (2017). Movilidad, utopía y lugares híbridos en Los Andes del sur de Chile. Revista invi, 32(91), 141-160. https://doi.org/10.4067/s071883582017000300141

Hunt, S., Benford, R., \& Snow, D. (1994). Marcos de acción colectiva y campos de identidad en la construcción social de los movimientos. En E. Laraña \& J. Gusfield (Eds.), Los nuevos movimientos sociales: de la ideología a la identidad (pp. 221-249). Madrid: CIS.

Iglesias, P. (2005). Un nuevo poder en las calles. Repertorios de acción colectiva del movimiento global en Europa. De Seattle a Madrid. Política y sociedad, 42(2), 63-93. Recuperado de http://revistas.ucm.es/index. php/POSO/article/view/POSO0505230063A

Inglehart, R. (1991). El cambio cultural en las sociedades industriales avanzadas. Madrid: CIS. Siglo XXI. ISBN 8474761603 , 9788474761603

Johnston, H., Laraña, E., \& Gusfield, J. (1994). Identidades, ideologías y vida cotidiana en los nuevos movimientos sociales. En E. Laraña \& J. Gusfield (Eds.), Los nuevos movimientos sociales: de la ideología a la identidad (pp. 3-42). Madrid: CIS.
Kawulich, B. (2005). La observación participante como método de recolección de datos. Forum: Qualitative Social research, Sozialforschung, 6(2). Recuperado de http://www.qualitative-research.net/index. php/fqs/article/view/466/999

Lazo, A. (2012). Entre el territorio de proximidad y la movilidad cotidiana: los anclajes y el territorio de proximidad como soporte y recurso para las prácticas de movilidad de los habitantes de la ciudad de Santiago de Chile (Tesis doctoral, Université Toulouse le Mirail-Toulouse II, Francia). Recuperada de https://hal. archives-ouvertes.fr/tel-00711072/

Le Bot, Y. (2009). El zapatismo, primera insurrección contra la globalización neoliberal. En M. Wieviorka (Comp.), Otro mundo... Discrepancias, sorpresas y derivas de la antimundialización (pp. 155169). México: FCE.

Litfin, K. (2009). Reinventing the future. The global ecovillage as holistic knowledge community. En G. Kütting \& R. Lipschutz (Eds.), Environmental governance: power and knowledge in a local global world (pp. 124-142). New York: Roudledge. Recuperado de https://faculty.washington. edu/litfin/research/Reinventing.pdf

Lizcano, E. (mayo, 2003). Imaginario colectivo y análisis metafórico. En Conferencia inaugural del Primer Congreso Internacional de Estudios sobre Imaginario y Horizontes Culturales que se celebró en la Universidad Autónoma del Estado de Morelos. Cuernavaca, México. Recuperado de http://www.unavarra.es/ puresoc/pdfs/c_salaconfe/SC-Lizcano-2. pdf

Lombardozzi, V. (2017). Nuevas reflexiones sobre comunidad y sociedad: el caso de la ecoaldea Piuke Ko. Persona \& sociedad, 31(1), 27-47. Recuperado de 
http://personaysociedad.cl/ojs/index.php/ pys/article/view/290/213

López, A. (1999). Los acuerdos de San Andrés y los gobiernos autónomos en Chiapas. Espiral, estudios sobre estado y sociedad, V (14), 127-145. Recuperado de http://www.redalyc.org/articulo. oa?id=13851405

McAdam, D. (1999). Marcos interpretativos y tácticas utilizadas por los movimientos: dramaturgia estratégica en el movimiento americano pro-derechos civiles. En D. McAdam, J. McCarthy, \& M. Zald (Eds.), Movimientos sociales, perspectivas comparadas (pp. 475-496). Madrid: Istmo.

Meijering, L. (2012). Ideals and practices of european ecovillages. En A. Marcus \& F. Wagner (Eds.), Realizing utopia: Ecovillage endeavors and academic approaches. Rachel Carson center perspectives, 8, 31-41. Recuperado de http://www.environmentandsociety.org/ sites/default/files/seiten_aus_layout_ issue8_new-4_0.pdf

Melucci, A. (1983). Mouvements sociaux, mouvements post-politiques. International review of community development, 10, 1330. https://doi.org/10.7202/1034652ar

Melucci, A. (1994a). ¿Qué hay de nuevo en los nuevos movimientos sociales? En E. Laraña \& J. Gusfield (Eds.), Los nuevos movimientos sociales: de la ideología a la identidad (pp. 119-149). Madrid: CIS.

Melucci, A. (1994b). Asumir un compromiso: identidad y movilización en los movimientos sociales. Zona abierta, 69, 153-180.

Melucci, A. (1999). Acción colectiva, vida cotidiana y democracia. México D.F.: El colegio de México, Centro de estudios sociológicos.
Miller, E. \& Bentley, K. (2012). Leading a sustainable lifestyle in a "non-sustainable world' Reflections from Australian ecovillage and suburban residents. Journal of education for sustainable development, 6(1), 137-147. https://doi. org/10.1177/097340821100600120

Moreno, C. \& Rovira, C. (2009). Imaginarios: Desarrollo y aplicaciones de un concepto crecientemente utilizado en las Ciencias Sociales. Programa de Naciones Unidas para el Desarrollo, New York. Recuperado de http://www. revistahumanum.org/revista/wp-content/ uploads/2012/02/08_RPPLAC_HD.pdf

Mueller, C. (1994). Identidades colectivas $\mathrm{y}$ redes de conflicto. El origen de las movilizaciones de las mujeres en Estados Unidos, 1960-1970. En E. Laraña \& J. Gusfield (Eds.), Los nuevos movimientos sociales: de la ideología a la identidad (pp. 287-319). Madrid: CIS

Nogué, J. (1988). El fenómeno neorrural. Agricultura y sociedad, 47, 145-175. Recuperado de https://www.mapa.gob.es/ ministerio/pags/biblioteca/revistas/pdf ays/a047_06.pdf

O'Connor, J. (2000). ¿Es posible el capitalismo sostenible? Papeles de población, 6(24), 9-35. Recuperado dehttp:// www.scielo.org. $\mathrm{mx} / \mathrm{scielo}$.php? script $=$ sci_ arttext\&pid=S1405-74252000000200002

Oslender, U. (2010). La búsqueda de un contra-espacio: ¿hacia territorialidades alternativas o cooptación por el poder dominante? Geopolitica(s) 1(1), 95114. Recuperado de https://revistas. ucm.es/index.php/GEOP/article/view/ GEOP1010120095A

Paredes, J. P. (2013). Movilizarse tiene sentido: Análisis cultural en el estudio de movilizaciones 
sociales. Psicoperspectivas, 12(2), 16-23. http://dx.doi.org/10.5027/ psicoperspectivas - Vol1 1 - Is sue 2fulltext-279

Pereira. C. (2011). Representación del movimiento global de ecoaldeas en internet. España: Editorial Académica Española. ISBN 13: 978-3-8454-8727-4. ISBN 10: 3845487275

Pereira. C. (2013). Participación y acción colectiva en los movimientos globales de ecoaldeas y permacultura. Revista Latinoamericana de psicología, 45(3), 401-413. http://dx.doi.org/10.14349/rlp. v45i3.1482

Pereira, C. \& Bernete, F. (2017). Comunicación y marcos de acción colectiva en el movimiento global de ecoaldeas. Mediaciones sociales, 16, 11-26. https://doi.org/10.5209/meso.58106

Pérez, M. (1994). "Cuando lleguen los días de la cólera" (Movimientos sociales, teoría e historia). Zona Abierta, 69, 51120. Recuperado de https://studylib. es/doc/6147948/cuando-lleguen-losd $\%$ C3\%ADas-de-la-c\% $\%$ C3\%B3lera

Pinto, J, Candina, A., \& Lira, R. (1999). Historia contemporánea de Chile, Tomo II. Actores, identidad y movimiento. En G. Salazar \& J. Pinto (Eds.). Santiago: Lom ediciones. ISBN: 9562821749

Piñeiro, D. (2004). En busca de la identidad. La acción colectiva en los conflictos agrarios de América Latina. Buenos Aires: Colección Becas CLACSO-ASDI. ISBN: 987-118308-9. Recuperado de http://biblioteca.clacso. edu.ar/clacso/becas/20110120045806/ pineiro.pdf

Pleyers, G. (2009). Autonomías locales y subjetividades en contra del neoliberalismo: hacia un nuevo paradigma para entender los movimientos sociales. En F. Mestries, G. Pleyers \& S. Zermeño (Coords.), Los movimientos sociales: de lo local a lo global (pp. 129-156). Barcelona: Anthropos editorial \& Universidad Autónoma Metropolitana.

Pleyers, G. (2010). Alter-globalization: Becoming actors in a global age. Cambridge: Polity press. ISBN: 978-0-7456-4675-6

Programa de las Naciones Unidas para el Desarrollo (PNUD). (2015). Desarrollo humano en Chile. Los tiempos de la politización. Santiago de Chile. ISBN: 978956-7469-59-8

Porto-Gonçalves, C. (2001). Geografias. Movimientos sociales, nuevas territorialidades $y$ sustentabilidad. México: Siglo XXI. ISBN: 9682323037, 9789682323034

Porto-Gonçalves, C. (2008). De saberes e de territórios: diversidade e emancipação a partir da experiência latino-americana. En A. E. Ceceña (Coord.), De los saberes de la emancipación y de la dominación (pp. 37-52). Buenos Aires: CLACSO, Consejo latinoamericano de ciencias sociales.

Riechmann, J. \& Fernández, F. (1994). Redes que dan libertad: introducción a los nuevos movimientos sociales. Barcelona: Paidós Ibérica. ISBN: 84-493-0051-7

Salamanca, L. \& Silva, D. (2015). El movimiento de ecoaldeas como experiencia alternativa de Buen Vivir. Polis. (Santiago), 14(40), 209-231. https://doi.org/10.4067/ s0718-65682015000100011

Santos, B. (2001). Los nuevos movimientos sociales. Observatorio social de América Latina, 5, 177-184. Recuperado de http:// biblioteca.clacso.edu.ar/ar/libros/osal/osal5/ debates.pdf 
Taylor, S \& Bogdan, R. (1992). Introducción a los métodos cualitativos de investigación. Barcelona: Editorial paidós. ISBN: 84-7509-816-9

Tilly, Ch. \& Wood, L. (2010). Los Movimientos Sociales, 1768- 2008. Desde sus orígenes a Facebook. Barcelona: Editorial crítica. ISBN: 978-84-9892-045-1

Touraine, A. (1994). Crítica de la modernidad. Argentina: Fondo de cultura económica. ISBN 10: 9505572042. ISBN 13: 9789505572045

Touraine, A. (1997). ¿Podremos vivir juntos? La discusión pendiente: el destino del hombre en la aldea global. Argentina: Fondo de cultura económica.

Trainer, T. (2002). Debating the significance of the global eco-village movement: A reply to Takis Fotopoulos. Democracy \& nature: International journal of inclusive democracy, 8, 1. Recuperado de https:// www.democracynature.org/vol8/takis trainer.htm

Wacquant, L. (1997). Three pernicious premises in the study of the American Ghetto. International journal of urban and regional research, 21(2), 341-353. https:// doi.org/10.1111/1468-2427.00076

Wagner, P. (Agosto, 2013). Reconceptualization of modernity. Seminario Internacional del Doctorado en Ciencias Sociales de la Universidad de Chile. Conferencia llevada a cabo en Santiago, Chile.

Wagner, P. (Agosto, 2013). Reconceptualization of modernity. (Tesis Doctoral inédita). Universidad de Chile. Santiago de Chile.

Wallerstein, I. (2008). Historias y dilemas de los movimientos antisistémicos. Ciudad de México: Contrahistorias. ISBN: 978958-8454-02-3

Weber, M. (1995). El político y el cientifico. Madrid: Ediciones altaya. ISBN 10: 8448702174. ISBN 13: 978-8448702175

Žižek, S. (2011). Bienvenidos a tiempos interesantes. La Paz: Vicepresidencia del Estado Plurinacional de Bolivia. ISBN: 9788415313151

Zunino, H. \& Hidalgo, R. (2010). En busca de la utopía verde: migrantes de amenidad en la comuna de Pucón, IX Región de la Araucanía, Chile. Scripta Nova, XIV (331), 75. Recuperado de http://www.ub.edu/ geocrit/sn/sn-331/sn-331-75.htm

Zunino, H. \& Huiliñir-Curío, V. (2017). Utopías modernas y posmodernas en el sur de Chile: rupturas y continuidades. En R. Sánchez, R. Hidalgo, \& F. Arenas (Eds.), Reconociendo las geografias de América Latina y el Caribe (pp. 157-181). Santiago de Chile: Instituto de geografía UC. 